

\section{Sumário}

I. INTRODUÇÃO

The Datasphere and the Law: New Space, New Territories ...................................III Jean-Sylvestre Bergé e Stéphane Grumbach

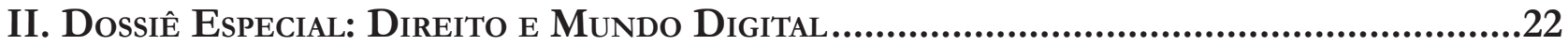

A. Criptomoedas e tecnologia blockchain ......................................................................23

Passado, presente e futuro da CRiptografia forte: DesenVolvimento tecnológico e

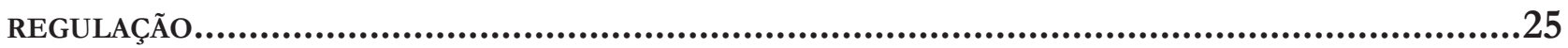
Jacqueline de Souza Abreu

Tratamento JuRídico Das CRIPTOMOEDAS: A DiNÂMiCA DOS BitCOINS E O CRIME DE LAVAGEM

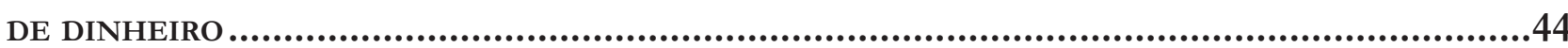
Mariana Dionísio de Andrade

TERRITÓRIO DAS CRIPTOMOEDAS: LIMITES À REGULAMENTAÇÃo ESTATAL QUANTO À CIRCULAÇÃO DE MOEDAS NO CIBERESPAÇO E POSSÍvEIS ALTERNATIVAS ..................................................61 Ranidson Gleyck Amâncio Souza

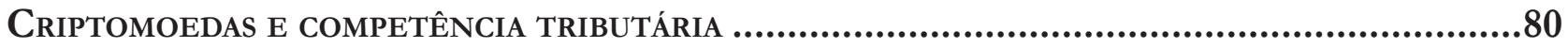
Guilherme Broto Follador

BitCoIn E A (IM)POSSIBILIDAde DE SUA PROIBIÇÃO: UMA VIOLAÇÃo À SOBERANIA Do EsTAdo?106 Rodrigo Valente Giublin Teixeira e Felipe Rangel da Silva

BlockChain e Agenda 2030

Danielle Mendes Thame Denny, Roberto Ferreira Paulo e Douglas de Castro

A reconstruÇão da JURISDição PELO ESPAÇO Digital: REDES SOCIAIS, BLOCKCHAIN E CRIPTOMOEDAS COMO PROPULSORES DA MUDANÇA.

Maria Edelvacy Pinto Marinho e Gustavo Ferreira Ribeiro

B. Proteção de dados e provedores de Internet

O tempo e O espaço. Fragmentos do marco Civil da internet: paradigmas de Proteção DA DIGNIDADE HUMANA 160 Maria Celeste Cordeiro Leite dos Santos e Marilene Araujo 
O PRojeto de Lei de PRoteção de dAdos PEssoais (PL 5276/2016) NO MUNDO do Big DATA: O FENÔMENO DA DATAVEILLANCE EM RELAÇÃo À UTILIZAÇÃO DE METADADOS E SEU IMPACTO NOS DIREITOS HUMANOS ................................................................................... 185

Elias Jacob de Menezes Neto, Jose Luis Bolzan de Morais e Tiago José de Souza Lima Bezerra

DignidADE HUMANA NA WEBESFERA GOVERNAMENTAL BRASILEIRA...................................200 Luciana Cristina Souza

CiberespaÇo E CONTEÚdo OFENSIVO GERAdo POR TERCEIROS: A PROTEÇão DOS DiREITOS DE PERSONALIDADE E A RESPONSABILIZAÇÃo CIVIL DOS PROVEDORES DE APLICAÇÃO, À LUZ DA JURisprudênCIA do Superior Tribunal de JustiçA................................................ 217 Cristiano Colombo e Eugênio Facchini Neto

A responsabilidade CIVIL pelos atos autônomos da INTEligÊnCIA ARTIFICIAL: NOTAS iniciais sobre a resolução do Parlamento Europeu ...........................................239 Thatiane Cristina Fontão Pires

Rafael Peteffi da Silva

SHARENTING, LIBERDADE DE EXPRESSÃO E PRIVACIDADE DE CRIANÇAS NO AMBIENTE DIGITAL: O PAPEL DOS PROVEDORES DE APLICAÇÃo NO CENÁRIO JURÍDICO BRASILEIRO. 256 Fernando Büscher von Teschenhausen Eberlin

THE DICHOTOMY BETWEEN SMART METERING AND THE PROTECTION OF CONSUMER'S PERSONAL DATA IN BRAZILIAN LAW..

Lucas Noura Guimarães

O CYBERBULlying E OS LIMITES DA LIBERDADE DE EXPRESSÃO 295 Janile Lima Viana, Cinthia Meneses Maia e Paulo Germano Barrozo de Albuquerque

O Supremo Tribunal Federal e o discurso de ódio nas redes sociais: exercício de DIREITO VERSUS LIMITES À LIBERDADE DE EXPRESSÃO

Carlo José Napolitano e Tatiana Stroppa

ANÁlise COMPARAdA DE ESTRATÉgIAS DE ENFRENTAMENTO A “REVENGE PORN” PELO MUNDO .... 334 Natália Neris, Juliana Pacetta Ruiz e Mariana Giorgetti Valente

USO INDEVIDO DE REDES SOCIAIS E APLICATIVOS DE MENSAGENS INSTANTÂNEAS NO AMBIENTE LABORAL 
ENSAIO SOBRE A PROMESSA JURÍDICA DO ESQUECIMENTO: UMA ANÁLISE A PARTIR DA PERSPECTIVA DO PODER SIMBÓliCo DE BOURDIEU 368 Joana Machado e Sergio Negri

UMA AGENDA PARA O DIREITO AO ESQUECIMENTO NO BRASIL. 384 Bruno de Lima Acioli e Marcos Augusto de Albuquerque Ehrhardt Júnior

NÃo AdIANTA NEM TENTAR ESQUECER: UM ESTUdo SOBRE O DIREITO AO ESQUECIMENTO...... 412 José Augusto Fontoura Costa e Geraldo Miniuci

A aplicaÇão do direito ao ESQUecimento aos agentes delitivos: uma ANÁlise aCERCA da PONDERAÇÃO ENTRE O DIREITO À IMAGEM E AS LIBERDADES DE EXPRESSÃO E DE INFORMAÇÃO437 Paulo Afonso Cavichioli Carmona e Flávia Nunes de Carvalho Cavichioli Carmona

DiREITO AO ESQUECIMENTO: NA SOCIEDADE INFORMACIONAL HÁ ESPAÇO PARA O EPÍLOGO DA MÁQUINA DE TORTURA KAFKIANA?

Alexandre Antonio Bruno da Silva e Marlea Nobre da Costa Maciel

ESQUECIMENTO, INTERNET E “PREFERÊNCIA” DA INFORMAÇÃO: POSSIBILIDADES DE APLICAÇÃO DA DOUTRINA DOS PREFERRED RIGHTS DA JURISPRUDÊNCIA NORTE-AMERICANA AO CASO BRASILEIRO 484

Maria Vital da Rocha, Isaac Rodrigues Cunha e Karin de Fátima Rodrigues Oliveira

D. Propriedade intelectual 510

Direitos AUtorais E MÚSICA: TECNOLOGIA, DiREITO E REGUlaÇão Marcia Carla Pereira Ribeiro, Cinthia Obladen de Almendra Freitas e Rubia Carneiro Neves

Direito AUTORAL NA CIBERCUlTURA: UMA ANÁLISE Do ACESSO AOS BENS IMATERIAIS A PARTIR DAS LICENÇAS CREATIVE COMMONS 4.0.

Gabriela Maia Rebouças e Fernanda Oliveira Santos

E. Políticas públicas e novas tecnologias.

SALTO DIGITAL NAS POLÍTICAS PÚBLICAS: OPORTUNIDADES E DESAFIOS .561 Marcelo D. Varella, Clarice G. Oliveira e Frederico Moesch

Fostering E-gOVERnMENT IN BRAZIL: A CASE STUdY OF DIGITAL CERTIFICATION ADOPTION.585 Lamartine Vieira Braga

DEMOCRATIZAÇÃo NA ERA Digital: DESAFIOS PARA UM DiÁlOgo CONSCIENTE E IGUALITÁRIO.602 Raquel Cavalcanti Ramos Machado e Laura Nathalie Hernandez Rivera 
REDES SOCIAIS E CROWDSOURCING CONSTITUCIONAL: A INFLUÊNCIA DA CIBERDEMOCRACIA SOBRE A GÊNESE E A INTERPRETAÇÃO DE NORMAS CONSTITUCIONAIS ...................................... 618 Igor Ajouz

MARCo CIVIL DA INTERNET E POLÍTICA PÚbliCA DE TRANSPARÊNCIA: UMA ANÁLISE DA E-DEMOCRACIA E DO COMPLIANCE PÚBLICO.

Juliana Costa Zaganelli e Wallace Vieira de Miranda

Políticas públicas bRasileiras de COMPUTAÇÃo EM NUVEM: ANÁLISE DOCUMENTAL dos RELATÓRIOS DO GLOBAL CLOUD COMPUTING SCORECARD

Lucas dos Santos Costa e Marcos Fernando Machado de Medeiros

O uso monopolista do Big Data POR EMpresas de aplicativos: políticas públicas para UM DESENVOLVIMENTO SUSTENTÁVEL EM CIDADES INTELIGENTES EM UM CENÁRIO DE ECONOMIA CRIATIVA E DE LIVRE CONCORRÊNCIA...................................................................6 672 José Antonio Remedio e Marcelo Rodrigues da Silva

1. Introdução

2. A urbanização das cidades e a sociedade em rede: economia criativa, colaborativa e compartilhada como formas de concretização de funções sociais da cidade.

4. Concorrência e Big Data Business relevantes às Smart Cities: estudo de caso envolvendo a aquisição do Waze pelo Google

5. Considerações finais

Referências

III. OUTROS TEMAS

COMO SALVAR O SISTEMA DE REPERCUSSÃo GERAL: TRANSPARÊNCIA, EFICIÊNCIA E REALISMO NA escolha do Que o Supremo Tribunal Federal vai Julgar.. .696 Luís Roberto Barroso e Frederico Montedonio Rego

Precariedade do sistema penitenciário brasileiro como base temática para a proibição OU LEGALIZAÇÃO DAS DROGAS. 715

Lilian Rose Lemos Rocha e José Eduardo Cardozo

A terceira margem do constitucionalismo republicano: uma Crítica A Frank Michelman. .732

Daniel Barcelos Vargas

Medida PRovisória E CONTROLE DE CONSTITUCIONALIDADE: RELEVÂNCIA, URGÊNCIA E PERTINÊNCIA TEMÁTICA

Clarice G. Oliveira e José Levi Mello do Amaral Júnior 
ОвJETO E CONCEITO DO DIREITO ADMINISTRATIVO: REVISÃo CRÍTICA...................................765 Carlos Bastide Horbach

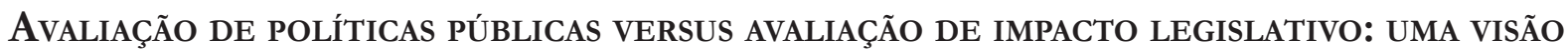
DICOTÔMICA DE UM FENÔMENO SINGULAR

Aparecida de Moura Andrade e Héctor Valverde Santana

LOS AVATARES DEL INTERÉS DEFINIDO EN TÉRMINOS DE PODER EN LA FORMULACIÓN DE LAS POLÍTICAS PÚBLICAS

Louis Valentin Mballa

CONSEQUENCIALISMO JUdicial NA MODUlaÇão DE EFEITOS DAS DECISÕES DECLARATÓRIAS DE INCONSTITUCIONALIDADE NOS JULGAMENTOS DE DIREITO TRIBUTÁRIO 819

Fernando Leal e Daniela Gueiros Dias

JudicializaÇão da SAÚde: A dignidade da PESSOA HuMana E A ATUAÇão do Supremo Tribunal Federal no caso dos medicamentos de alto custo

Fabricio Veiga Costa, Ivan Dias da Motta e Dalvaney Aparecida de Araújo 


\title{
Ciberespaço e conteúdo ofensivo gerado por terceiros: a proteção dos direitos de personalidade e a responsabilização civil dos provedores de aplicação, à luz da jurisprudência do Superior Tribunal de Justiça*
}

\author{
Cyberspace and offensive content generated \\ by third parties: the protection of personality \\ rights and the civil liability of application \\ providers under the jurisprudence of the \\ Brazilian Superior Tribunal of Justice
}

Cristiano Colombo**

Eugênio Facchini Neto***

\section{Resumo}

O estudo busca, em sua primeira parte, refletir sobre as características do ciberespaço, destacando sua enorme contribuição para a expansão do exercício da liberdade de expressão, aumentando os níveis da comunicação a patamares nunca antes visto. Diante da escassez de filtros a tal exercício, passou-se a perceber a ocorrência de danos a direitos de personalidade, especialmente honra, imagem e privacidade, em razão de postagens e manifestações nas plataformas virtuais, ofensivas a direitos de terceiros. Um dos objetivos do presente estudo é justamente analisar qual a resposta dos ordenamentos jurídicos para possibilitar a compatibilização do exercício da liberdade de expressão sem censura, com o resguardo dos direitos de terceiros eventualmente atingidos por tal exercício. $\mathrm{Na}$ segunda parte, enfoca-se, mais especificamente, a aplicação ao tema do instituto da responsabilidade civil e da evolução que sofreu nesse contexto, passando de objetiva, para vicária, e, atualmente, subjetiva. Essa análise será feita, principalmente, com base na análise de julgados do Superior Tribunal de Justiça, identificando-se cinco acórdãos paradigmáticos, envolvendo questões distintas, que contribuem para a construção do tratamento jurídico do tema em comento. Concluir-se-á que o STJ, com uma jurisprudência estável, vem conseguindo compatibilizar, razoavelmente, o exercício sem censura da liberdade de expressão no mundo virtual com o resguardo dos direitos de personalidade de eventuais prejudicados por tal exercício. Quanto à metodologia, a abordagem da pesquisa foi teórica, exploratória e descritiva. Como procedimento técnico, utilizou-se a pesquisa bibliográfica, nacional e estrangeira, bem como jurisprudencial.

Palavras-chave: Ciberespaço. Conteúdo Gerado por Terceiros. Responsabilidade Civil. 


\section{Abstract}

The study seeks, in its first part, to reflect on the characteristics of cyberspace, highlighting its enormous contribution to the expansion of the exercise of freedom of expression, increasing communication to levels never before seen. Faced with the scarcity of filters for such an exercise, we began to perceive the occurrence of damages to personality rights, especially honor, image and privacy, due to postings on virtual platforms, offensive to third party rights. One of the objectives of the present study is precisely to analyze the response of legal systems in order to make compatible the exercise of freedom of expression without censorship, with the protection of the rights of personality of third parties that may be affected by such exercise. In the second part, it focuses more specifically on the application to the theme of the institute of civil liability and the evolution that it suffered in that context, going from objective, to vicarious, and, currently, based on fault. This analysis will be made mainly from the analysis of judgments of the Superior Court of Justice, identifying five paradigmatic judgments, involving different issues, which contribute to the construction of legal treatment of the subject in question. It will be concluded that the STJ, with a stable jurisprudence, has managed to reasonably reconcile the uncensored exercise of freedom of expression in the virtual world, with the protection of the rights of personality of any persons harmed by such exercise. As for the methodology, the research approach was theoretical, exploratory and descriptive. As a technical procedure, bibliographical research, both national and foreign, as well as case law were used.

Keywords: Cyberspace. Third Parties Generated Content. Civil Responsibility.

\section{INTRODUÇÃo}

O desenvolvimento de um mundo virtual paralelo ao mundo físico trouxe transformações impressionantes ao modo de vida da humanidade. A revolução da informática acarretou uma revolução na esfera da comunicação. Nunca como antes as pessoas puderam se comunicar tão fácil, ampla e difusamente como agora. A liberdade irrestrita de expressão encontrou seu habitat natural na rede mundial de computadores e nas suas inúmeras plataformas.

No mundo virtual da web, torna-se muito difícil aos detentores do poder, político ou econômico, controlar as informações que transitam pela rede.

Esse lado positivo, caracterizado pela facilidade com que se obtêm informações úteis e pela instantaneidade da manifestação do pensamento, dissolvendo noções de espaço e de território, é contrabalançado, porém, pela ausência de filtros àquilo que é divulgado na rede. Ao lado de informações valiosas e precisas, postam-se, também, informações falsas. A facilidade com que se pode atingir a honra de pessoas, violar sua intimidade ou desrespeitar seu direito à imagem é igualmente espantosa.

Desafio dos tempos modernos, portanto, é encontrar o justo equilíbrio entre a garantia dessa maravilhosa liberdade de expressão, sem censuras, com a devida proteção aos direitos de personalidade que se tornam vulneráveis nesse ambiente virtual.

O presente trabalho é dividido em dois capítulos, cada um contendo subdivisões. No primeiro capítulo, apresentar-se-á, inicialmente, o tema do ciberespaço, descrevendo suas características, bem como analisando sua relação com o direito estatal. Na segunda parte, aprofundar-se-á o estudo dos conteúdos ofensivos gerados por terceiros, nas plataformas dos provedores de aplicação, fazendo-se as distinções pertinentes.

No segundo capítulo, abordar-se-á a evolução da responsabilidade civil no campo do ciberespaço e suas tendências contemporâneas, para, posteriormente, analisar como se coloca, nesse quadro genérico, a situação atual da responsabilidade civil dos provedores de aplicação, no Brasil, com base na análise de cinco casos 
paradigmáticos julgados pelo Superior Tribunal de Justiça.

Quanto à metodologia, a abordagem da pesquisa será teórica, exploratória e descritiva. Os procedimentos técnicos envolveram pesquisa bibliográfica nacional e estrangeira sobre os temas tratados, bem como a jurisprudência do STJ a respeito.

\section{Ciberespaço e conteúdo ofensivo gerado por terceiros}

\subsection{Ciberespaço}

Em 1962, no auge da guerra fria, a agência de pesquisa Advanced Research Projects Agency (ARPA) foi encarregada pelo governo norte-americano para realizar um sistema de comunicação capaz de transmitir dados mesmo na hipótese de um conflito nuclear. Ligando alguns computadores entre si, naqueles anos, nasceu a rede Arpanet, que está na origem da rede Internet (INTERconnected NETworks). Esta, por meio de uma série de computadores conectados entre si, permite a comunicação em rede, utilizando uma linguagem comum, ditada pelo protocolo do modelo TCP/IP ${ }^{1}$. Esse protocolo (Transmission Control Protocol/Internet Protoco) foi registrado em 1973 por Vinton Cerf, do Departamento de Pesquisa avançada da Universidade da Califórnia e responsável pelo projeto ${ }^{2}$. Pode-se dizer ser esta a data de nascimento da internet, que no Brasil chega na década de noventa.

Essa tecnologia da informação, ao promover a aceleração do processo comunicacional, impacta, diretamente, as relações sociais ${ }^{3}{ }^{4}$ Tempo e espaço inserem-se em um novo contexto, havendo, simultaneamente, o espaço físico e espaço virtual, este denominado por William Gibson, em sua novela "Neuromancer" "ciberespaço" (cyberspace). Segundo Marcondes Filho, para transitar no ciberespaço, não é preciso utilizar as pernas: bastam os dedos e o cérebro. $\mathrm{O}$ "espaço virtual jamais existiu em qualquer época do passado, nem poderia ser imaginado antes. Só se tem acesso a ele pela tela do computador, que funciona como um buraco, uma porta, um túnel." Trata-se de "um espaço que se visita permanecendo-se fisicamente no mesmo lugar de origem". ${ }^{6}$

Pierre Lévy igualmente salienta esse viés informacional do ciberespaço, afirmando que "o ciberespaço é o novo meio de comunicação que surge da interconexão mundial dos computadores", envolvendo o "universo oceânico de informações que ela abriga".

De fato, diferentemente do espaço físico, o ciberespaço conta com "uma arquitetura caracterizada por sua maleabilidade". ${ }^{8}$ Em poucos segundos, informações pessoais, financeiras, vídeos e áudios atravessam o

1 Sobre essa origem e seus desdobramentos, v. GAUDENZI, Andrea Sirotti. Diritto all'oblio: responsabilità e risarcimento del danno. Santarcangelo di Romagna: Maggioli Editore, 2017. p. 129s.

2 PAESANI, Liliana Minardi. Direito e Internet. Liberdade de informação, privacidade e responsabilidade civil. 5. ed. São Paulo: Atlas, 2012. p. 10.

3 BAUMAN, Zygmunt; MAY, Tim. Aprendendo a pensar com a sociologia. Tradução de Alexandre Werneck. Rio de Janeiro: Zahar, 2010. p. 175.

4 Com base em diversas pesquisas recentes, Marcos Rogério de Souza afirma que "as pessoas confiam mais nos rankings de produtos das redes sociais que participam do que nos rankings do Google. $78 \%$ dos consumidores confiam nas recomendações de seus pares" - SOUSA, Marcos Rogério de. Responsabilidade Civil pelo Conteúdo das Informações Transmitidas pela Internet. In: LOPEZ, Teresa Ancona; LEMOS, Patrícia Faga Iglecias; RODRIGUES JUNIOR, Otavio Luiz (Coord.). Sociedade de Risco e Direito Privado: desafios normativos, consumeristas e ambientais. São Paulo: Atlas, 2013. p. 678-698, 680.

5 New York: Ace Books, 1984.

6 MARCONDES FILHO, Ciro. O rosto e a máquina. São Paulo: Paulus, 2013. p. 87-88.

7 LÉVY, Pierre. Cibercultura. Tradução de Carlos Irineu da Costa. São Paulo: Editora 34, 2008. p. 17.

8 LORENZETTI, Ricardo Luis. Teoria da decisão judicial: fundamentos de direito. Tradução de Bruno Miragem. Notas de Claudia Lima Marques. São Paulo: Revista dos Tribunais, 2010. p. 50. 
globo. Por meio de "chat" podem dois usuários conectados em diferentes locais, separados por enormes distâncias, comunicaram-se em tempo real. ${ }^{9}$ Nesse ambiente, a informática e a telecomunicação permitem que dados cruzem mares, continentes, hemisférios, criando uma "rede gigantesca de transmissão", conectando pessoas em qualquer lugar do globo, constituindo-se um universo virtual paralelamente ao físico. ${ }^{10}$

$\mathrm{Na}$ medida em que os seres humanos alimentam esse universo de dados e informações, a tecnologia modificou a natureza do diálogo humano. ${ }^{11}$ A mudança do analógico para o digital torna os dados voláteis e manipuláveis. Já não confinamos mais os dados num hardware físico, diante da crescente utilização do armazenamento em nuvens. Há uma crescente desmaterizalização e desterritorialização. "Espaços-de-tempo" tornam-se cada vez menores. Trata-se de um "novo tempo e habitat de espírito". ${ }^{12}$

Erik Jayme, aliás, destaca a extinção das fronteiras que marca a Sociedade da Informação, pois "qualquer um pode facilmente se libertar das amarras de sua existência limitada: velocidade, ubiquidade, liberdade; o espaço, para a comunicação, não existe mais." ${ }^{\text {"13 }}$

Por outro lado, focando aspecto diverso, Klaus Schwab aponta a plataforma como uma forma de facilitação entre os internautas, no sentido de aproximar interessados em fornecer e em adquirir ampla gama de produtos e serviços. ${ }^{14}$ Isso acaba sendo outra oportunidade de negócio, pois "enquanto as páginas de webmail são acessadas, o provedor de internet assimila os dados das mensagens recebidas e enviadas, e os oferece aos anunciantes, de modo que publicidades customizadas apareçam durante a verificação das caixas de entrada". Por outro lado, os sites de busca tem papel destacado nesse processo, pois segundo pesquisas, "78\% dos acessos à internet passam por sites de busca". ${ }^{15}$

Importa salientar que a maleabilidade do ciberespaço, sua fluidez, sua impossibilidade de estar contido, levou a estudiosos a defender que no ciberespaço, "operam e se autoproduzem regras sociais de comportamento suas e próprias", oriunda de uma autopoiese, com normas autogeradas, decorrentes de fontes não-estatais, ${ }^{16}$ na linha de uma Lex Informatica ${ }^{17}$. A originalidade e peculiaridade da internet levaria, segundo esse entendimento, à conclusão de que o ciberespaço não deveria ser objeto de regulação estatal, sendo regido por autorregulação. Assim, em surgindo conflitos, os consumidores do ciberespaço invocariam a "netiqueta", ou seja, "leis consuetudinárias - não escritas", com uma "forte moral social"18. ${ }^{19}$

Essa posição de recusa à intervenção estatal dá-se por grande parte dos internautas ${ }^{20}$, que desejavam

9 CAVAZOS, Edward A.; MORIN, Gavino. Cyber-space and The Law: Your Rights and Duties in the On-Line World. Massachusetts: Massachusetts Institute of Technology, 1996. p. 2.

10 SANTAELLA, Lucia. Linguagens líquidas na era da mobilidade. São Paulo: Paulus, 2011. p. 32-39.

11 LASICA, J. D. Identity in the age of Cloud Computing. Washington: The Aspen Institute, 2009. p. 9. Nas palavras do autor: This changes the entire nature of the human dialogue.

12 AZAMBUJA, Celso Candido de. Psiquismo digital sociedade, cultura e subjetividade na era da comunicação digital. Nova Petrópolis: Nova Harmonia, 2012. p. 1 e 390.

13 JAYME, Erik. O direito internacional privado do novo milênio: a proteção da pessoa humana face à globalização. Cadernos do Programa de Pós-Graduação em Direito - PPGDir./UfRGS, Porto Alegre, v. 1, n. 1, p. 133-146, mar. 2003. p. 134.

14 SCHWAB, Klaus. The fourth industrial revolution. Genebra: Wold Economic Forum, 2016. p. 13.

15 MACHADO, Alexandre Fragoso. Os Anunciantes, os Sites de Busca e os Links Patrocinados: Direito do Consumidor e Responsabilidade Civil. In: LOPEZ, Teresa Ancona; LEMOS, Patrícia Faga Iglecias; RODRIGUES JUNIOR, Otavio Luiz (Coord.). Sociedade de Risco e Direito Privado: desafios normativos, consumeristas e ambientais. São Paulo: Atlas, 2013. p. 644-677, 649.

16 ROSSELLO, Carlo. Riflessioni. De Jure Condendo in materia di responsabilità del provider. Il Diritto dell'Informazione e Dell'Informatica, Roma, v. 26, n. 6, p. 617-629, nov./dez. 2010. p. 618.

17 LESSIG, Lawrence. Code Version 2.0. New York: Lawrence Lessig CC Attribution-ShareAlike, 2006. Versão Kindle. p. 214.

18 LÉVY, Pierre. Cibercultura. Tradução de Carlos Irineu da Costa. São Paulo: Editora 34, 2008. p. 128.

19 Newton De Lucca, a propósito, lembra antiga decisão de uma Corte Federal de Apelação norte-americana que referiu que "por ser a maior forma de expressão já desenvolvida até agora, a Internet merece a maior proteção possível contra a intromissão governamental...”. DE LUCCA, Newton. Alguns aspectos da responsabilidade civil no âmbito da Internet. In: DINIZ, Maria Helena; LISBOA, Roberto Senise (Coord.). O Direito Civil no Século XXI. São Paulo: Saraiva, 2003. p. 423-470, 438/439.

20 Sobre a utilização de metadados pelo Estado: BEZERRA, Tiago José de Souza Lima; MENEZES NETO, Elias Jacob de; MORAIS, Jose Luis Bolzan de. O projeto de lei de proteção de dados pessoais (PL 5276/2016) no mundo do big data: o fenômeno da dataveillance em relação à utilização de metadados e seu impacto nos direitos humanos. In: Revista Brasileira de Políticas Públicas, 
manter seu "espaço de liberdade"21, ou seu "mundo de liberdade"22. Todavia, revelava-se impossível a manutenção da possibilidade de fruição de tal liberdade irrestrita, com a restrição do campo de atuação do Direito, na medida em que, cada vez mais, as relações sociais migraram para o mundo da Internet. Disso decorre a potencial ocorrência de conflitos, que, necessariamente, deverão ser solucionados à luz de critérios jurídicos (levando-se em conta que o Direito é algo bem maior do que sua fonte legislativa).

A respeito do tema, Lawrence Lessig havia, também, sustentado uma posição não intervencionista do direito estatal, buscando garantir uma certa independência ao ciberespaço ${ }^{23}$. Todavia, acabou reconhecendo que a "liberdade não é a ausência do Estado", revelando uma "Second Life"24, uma verdadeira realidade online. Abandonou-se, portanto, a "ilusión éphémère de la zone de non-droit" 25 , até porque, "na ausência de regras, o que se tem é a barbárie, que é o contrário do direito"26.

A necessidade de uma legislação própria, dado o "aparecimento muito rápido de novos problemas"27, faz com que os governos, paulatinamente, venham a regular o mundo virtual, assim como já ocorrido no mundo físico. ${ }^{28}$ Bruno Miragem adverte sobre a importância de sua regulação, especialmente diante das "novas questões que decorrem diretamente destas inovações tecnológicas, como o comércio eletrônico, a proteção dos direitos autorais ou a proteção de crianças quanto ao conteúdo divulgado na rede mundial de computadores". ${ }^{29}$

Dessa forma, relações jurídicas migram do físico para o virtual, devendo o operador do Direito compreender as peculiaridades desse novo mundo se quiser ser eficaz em sua tentativa de enquadrá-lo no mundo jurídico. Dentre as peculiares dificuldades da regulamentação jurídica da internet, costumam ser apontados dois grandes obstáculos: seu caráter global (desterritoriedade) e sua estrutura não hierarquizada ${ }^{30}$.

O caráter global e desterritorializado da internet pode acarretar problemas de fixação da competência do juízo. Na Europa, há precedentes holandeses, austríacos e franceses apontando para a tendência de reconhecer a competência do local onde o dano ocorreu. Precedente italiano aponta para a presunção de que os danos ocorreram no local de domicílio da vítima ${ }^{31}$.

v. 7, n. 3, 2017.

21 MANCINI, Anna. Justice et internet: une philosophie du droit pour le monde virtuel. Paris: Buenos Books International, 2004. Versão Kindle. posição 77.

22 FRANZONI, Massimo. Il riscarcimento del danno per lesione dei diritti della personalità su internet In: NIVARRA, Luca; Ricciuto, Vincenzo (Org.). Internet e il diritto dei privati: persona e proprietà intelletuale nelle reti telematiche. Torino: Giappichelli, 2002. p. 127-136. p. 128.

23 LESSIG, Lawrence. Code Version 2.0. New York: Lawrence Lessig CC Attribution-ShareAlike, 2006. Versão Kindle. p. 165. Em suas palavras: "the society of this space would be a fully self-ordering entity, cleansed of governors and free from political hacks" - op. cit., p. 173

24 LESSIG, Lawrence. Code Version 2.0. New York: Lawrence Lessig CC Attribution-ShareAlike, 2006. Versão Kindle. p. 290. Esclareceu o autor que "Liberty in cyberspace will not come from the absence of the state. Liberty there, as anywhere, will come from a state of a certain kind. We build a world where freedom can flourish not by removing from society any self-conscious control, but by setting it in a place where a particular kind of self-conscious control survives. We build liberty as our founders did, by setting society upon a certain constitution" - op. cit., p. 185.

25 THIEFFRY, Patrick. Commerce électronique. Droit international et européen. Paris: Éditions Litec, 2002. p. 2.

26 LEWICKI, Bruno. Realidade Refletida: Privacidade e Imagem na Sociedade Vigiada. In: TEPEDINO, Gustavo; FACHIN, Luiz Edson (Coord.). O Direito e o Tempo: Embates Jurídicos e Utopias Contemporâneas. Rio de Janeiro: Renovar, 2008. p. 103-113.

27 ASCENSÃO, José de Oliveira. Estudos sobre direito da internet e da sociedade da informação. Coimbra: Almedina, 2001. p. $212-286$.

28 SCHMIDT, Eric; COHEN, Jared. A nova era digital: como será o futuro das pessoas, das nações e dos negócios. Tradução de Ana Beatriz Rodrigues, Rogério Durst. Rio de Janeiro: Intrínseca, 2013. posição 1.634.

29 MIRAGEM, Bruno. Responsabilidade por danos na sociedade de informação e proteção do consumidor: desafios atuais na regulação jurídica da internet. Revista de Direito do Consumidor, São Paulo, v. 70, p. 1-42, abr. 2009. Disponível em: <http://revistadostribunais.com.br/maf/api/tocectory?ndd=3\&tocguid=brroot\&stnew=true $>$. Acesso em: 24 jun. 2014. p. 2.

30 FURTADO, Gabriel Rocha. O marco civil da Internet: a construção da cidadania virtual. In: SCHREIBER, Anderson (Coord.). Direito e Mídia. São Paulo: Atlas, 2013. p. 236-254, p. 238.

31 Sobre esses precedentes, v. TELLINI, Denise Estrella. Regime de direito internacional privado na responsabilidade dos provedores de internet: Content Service Providers e Intermediary Service Providers pela qualidade dos serviços executados online. Porto Alegre: S. A. Fabris, 2006. p. 285-286.

No direito brasileiro, acórdão do Tribunal de Justiça do Rio Grande do Sul enfrentou a questão da competência da justiça brasilei- 
Aliás, na Europa, desde 1995 havia uma detalhada Diretiva (n. 95/46/CE) disciplinando a proteção de dados pessoais na rede mundial ${ }^{32}$. Essa Diretiva foi recentemente substituída pelo Regulamento EU 2016/679, do Parlamento Europeu e do Conselho Europeu, de 27.04.2016, mas que entrará em vigor em 25.05.2018. Dentre seus princípios de maior relevância, destacam-se o princípio da transparência, da accountability, da privacy by design e do direito ao esquecimento ${ }^{33}$. Tem sido referido que essa nova regulamentação protege os dados pessoais não apenas como aspecto de um direito fundamental da pessoa, como na Diretiva anterior, mas como verdadeiro interesse público europeu ${ }^{34}$.

\subsection{Conteúdo ofensivo gerado por terceiros}

No mundo virtual, provedores disponibilizam espaços de interação aos internautas, viabilizando a publicação de conteúdo, sem a imposição de controle prévio ou, mesmo, aplicação de filtros, em relação a tudo que é publicado. Dá-se vazão, assim, à liberdade de expressão (art. $5^{\circ}$, inc. IX, da Constituição Federal) no seu mais ilimitado sentido.

ra, em razão de perfil falso criado no domínio espanhol da Google. Como a vítima tinha domicílio também nesse Estado, afirmou-se a competência da justiça brasileira. O acórdão, na parte que interessa ao tema, está assim ementado:

APELAÇÃO CÍVEL. RESPONSABILIDADE CIVIL. GOOGLE BRASIL INTERNET LTDA. CRIAÇÃO DE BLOG DIFAMATÓRIO NO GOOGLE ESPANHA. POSSIBILIDADE DE RECLAMAÇÃO À FILIAL BRASILEIRA DO GOOGLE. COMPETÊNCIA DA JUSTIÇA BRASILEIRA. EXTENSÃO. INFORMAÇÕES INJURIOSAS MANTIDAS MESMO APÓS A "DENÚNCIA DE ABUSO” RELATADA PELA AUTORA. DANOS MORAIS CONFIGURADOS. [...]

2. AGRAVO RETIDO:

DA ALEGADA INCOMPETÊNCIA ABSOLUTA DA JUSTIÇA BRASILEIRA. Tratando-se de informações difamatórias contidas no mundo virtual, que não conhece fronteiras, não há como delimitar o alcance dessas informações e, por consequência, o limite territorial de sua repercussão. No caso, o dano teve repercussão no Brasil, local onde a autora também possui domicílio (profissional). COMPETÊNCIA DA JUSTIÇA BRASILEIRA afirmada, em razão do disposto no art. 88 do CPC/73, aplicável ao caso. Uma vez afirmada a competência da justiça pátria, é possível a determinação de retirada de conteúdo de site criado na filial espanhola da GOOGLE.

Há menos de um mês atrás, o plenário civil do Tribunal Supremo espanhol seguindo orientação do emblemático julgamento do Tribunal de Justiça da União Europeia, de maio de 2014, afirmou a competência da justiça espanhola para situação semelhante. Ou seja, adotou-se o entendimento de que não é exigível que o cidadão que teve lesado um seu direito fundamental em razão de indevida publicação de dados na rede mundial de computadores, deva mover sua demanda contra a sede norte-americana da GOOGLE ou contra as filiais nacionais da gigante corporação. Entender de outra forma tornaria caríssima e insuportavelmente lenta a proteção dos direitos fundamentais, praticamente inviabilizando, na prática, tal tutela que, para ser eficiente, depende de rápidas soluções.

As diversas filiais nacionais da GOOGLE, embora possam ter personalidade jurídica distinta, evidentemente integram a mesma gigante corporação e mantém fáceis contatos entre si. Como o produto com que trabalham não conhece fronteiras, situando-se num 'mundo plano' e ilimitado, o potencial risco de que conteúdos postados num determinado país violem direitos fundamentais de cidadão domiciliado em outro deve ser absorvido pela própria corporação. Esta certamente possui ágeis canais de comunicação entre suas diversas filiais nacionais, podendo eficazmente cumprir determinações judiciais para retirada de tais conteúdos.

DA LEGITIMIDADE PASSIVA. Tomando ciência da existência do blog falso, contendo conteúdo difamatório, sem proceder à sua retirada da internet, conforme solicitada pela autora na via administrativa (já que os fatos ocorreram antes da edição do Marco Civil da Internet), resta configurada sua legitimidade passiva para responder pela demanda.

$[\cdots]$

PRELIMINAR DESACOLHIDA, AGRAVO RETIDO DESPROVIDO E APELO PARCIALMENTE PROVIDO.

(TJRS, 9a CC, Ap. Cível n. 70068005966, Rel. Des. Eugênio Facchini Neto, j. em 27.04.2016).

32 Sobre a evolução do princípio da responsabilidade no sistema europeu de proteção de dados, desde a Convenção 108/1981 até o Regulamento de 2016, v. PARISI, Annamaria Giulia. Responsabilità e Sanzioni. In: SICA, Salvatore; D’ANTONIO, Virgilio; RICCIO, Giovanni Maria (a cura di). La nuova disciplina europea della privacy. Milanofiori Assago/Itália: Wolters Kluwer/CEDAM, 2016. p. 289-312. p. 293s.

33 Sobre o novo Regulamento, seus princípios, objetivos e desafios, v. IASELLI, Michele. Come esercitare il diritto all'oblio in internet : Le procedure extragiudiriali, la tutela d'urgenza, il risarcimento danni. Roma: Dike Giuridica Editrice, 2017. p. 47s. A questão do direito ao esquecimento é um tema que ganhou projeção e importância no mundo digital, onde não existem repartições temporais - passado, presente e futuro. Tudo é um presente contínuo, ao alcance de nossos dedos. Como disse Victor Mayer-Schönberger, "we forgive through forgetting, but the digital tools that surround us no longer let us do that - and instead brutally remind us again and again, long into our future, of the mistakes we've made in our past" - MAYER-SCHÖNBERGER, Victor. Delete: The Virtue of Forgetting in the Digital Age. Princeton: Princeton University Press, 2009. p. 202.

34 PIZZETTI, Franco. Privacy e il diritto europeo alla protezione dei dati personali: Il Regolamento europeu 2016/679. Torino: Giappichelli Editore, 2017. p. 4. 
M. Leonardi contextualiza a liberdade de expressão no mundo virtual. Após lembrar que se trata de um direito fundamental consagrado tanto na Constituição Federal brasileira quanto pelos tratados internacionais aos quais o Brasil aderiu, consistindo "na liberdade de, sem interferências, ter opiniões e de procurar, receber, transmitir informações e ideias por quaisquer meios, independentemente de fronteiras", destaca que "o livre fluxo de informações é essencial para a criatividade e inovação, gerando desenvolvimento social, cultural e econômico. As plataformas e serviços online exercem um papel fundamental nesse processo. ${ }^{35}$

Além da disposição constitucional, a liberdade de expressão, também, está contemplada entre os fundamentos do Marco Civil da Internet, diante da previsão do seu art. $2^{\circ}$. Pela sua redação e estrutura (a liberdade de expressão está prevista no caput e os demais fundamentos nos incisos), dá o legislador a entender que quis elegê-la como um fundamento superior em relação aos outros. Mas isso não é necessariamente uma verdade absoluta, já que o Marco Civil da Internet deve ser visto e aplicado à luz da Constituição Federal ${ }^{36}$, que alberga igualmente outros valores e princípios igualmente relevantes a serem resguardados. Quando em colisão, a solução passa pelo consagrado juízo de ponderação.

O fenômeno da participação multipessoal na construção do mundo virtual se intensificou com o advento da Web 2.0 $0^{37}$, que se caracteriza exatamente por esta maior interação do usuário. A partir de então, o internauta deixa de observar uma página da web como um outdoor, um painel, revelando uma conduta meramente passiva, e passa, também, a produzir conteúdo no ciberespaço. Em tempos passados, divulgar uma ideia era oneroso. Nos dias atuais, sem qualquer pagamento para entrar em uma comunidade, pois basta dispor de uma conexão à internet, o usuário opina, diverge, enfim, livremente se expressa, atingindo muitas pessoas, como se dá, por exemplo, em redes sociais como o Facebook.

Nesse contexto de liberdade do ciberespaço, a internet passa a viabilizar a ampla troca de ideias, através de fóruns de discussões, chats, posts, cujo ambiente é intermediado pelos próprios provedores. Os temas enfrentados no ciberespaço são variados, desde profundas reflexões científicas, interessantes informações, até questões do dia-a-dia, trivialidades, proporcionando um espaço público em que se desenvolvem debates e embates. Essa intensa troca de informações é extremamente valiosa.

O problema é que muitas vezes as postagens vêm carregadas de tons ofensivos. De fato, a internet possibilita que qualquer um possa acessar e manipular uma infinita quantidade de informações em relação a qualquer aspecto da vida social. Isso acarreta enormes benefícios, responsáveis pelo sucesso da rede, mas, igualmente, traz consigo oportunidades inéditas para a prática de atos ilícitos ${ }^{38}$, civis e criminais, com grande potencial de danos.

São inúmeras as plataformas onde os usuários da rede podem manifestar a sua opinião ou postar informações ou imagens e, potencialmente, lesar terceiros. É o que se passa a analisar.

\subsubsection{Redes Sociais}

Nas redes sociais, como o Facebook, por exemplo, o internauta pode, em seu perfil, criar uma publicação (escrever o que está pensando), publicar uma foto ou vídeo, realizar uma transmissão ao vivo (live), compartilhar, bem como manifestar aprovação ou desaprovação através de emoticons, que são ícones que

35 LEONARDI, Marcel. A garantia fundamental do direito à privacidade e à liberdade de expressão nas comunicações na condição ao pleno exercício do direito ao acesso à internet. In: LEITE, George Salomão; LEMOS, Ronaldo (Org.). Marco civil da internet. São Paulo: Atlas, 2014. p. 627.

36 TEIXEIRA, Tarcísio. Marco civil da internet comentado. São Paulo: Almedina, 2016. p. 27.

37 AZAMBUJA, Celso Candido de. Psiquismo digital sociedade, cultura e subjetividade na era da comunicação digital. Nova Petrópolis: Nova Harmonia, 2012. p. 673.

38 SOUSA, Marcos Rogério de. Responsabilidade Civil pelo Conteúdo das Informações Transmitidas pela Internet. In: LOPEZ, Teresa Ancona; LEMOS, Patrícia Faga Iglecias; RODRIGUES JUNIOR, Otavio Luiz (Coord.). Sociedade de Risco e Direito Privado: desafios normativos, consumeristas e ambientais. São Paulo: Atlas, 2013. p. 680-681. 
representam emoções.

Também é possível escrever nas publicações (posts) de outros usuários, bem como parabenizá-lo por seu aniversário ou por conquistas em seu trabalho ${ }^{39}$, e, inclusive, marcar pessoas, vinculando o que escreveu à timeline do usuário mencionado.

Confirmando o que se vê na casuística forense ${ }^{40}$, existem inúmeras possibilidades de, no ambiente de uma plataforma de um provedor de aplicação voltado à rede social, usuários, na qualidade de terceiros, pois não são provedores, tampouco seus prepostos, ofenderem direitos de personalidade alheios (especialmente honra, intimidade ou privacidade), até mesmo praticando ilícitos criminais ${ }^{41}$.

\subsubsection{Páginas de Notícias/Jornais digitais}

Internautas, também, se manifestam nos comentários de notícias, quando é possível encontrar espaço para que os leitores possam expressar o que pensam sobre determinado fato.

Saliente-se que todas as opiniões que compõem a linha editorial não são consideradas como conteúdos

39 Sobre ciberespaço e mundo do trabalho: LEMOS JUNIOR, Eloy Pereira; ALVES, Edmar Warlisson de Souza; FIUZA, César Augusto de Castro. Uso indevido de redes sociais e aplicativos de mensagens instantâneas no ambiente laboral. In: Revista Brasileira de Políticas Públicas, v. 7, n. 3, 2017.

40 RECURSO ESPECIAL. AÇÃO DE COMPENSAÇÃO DE DANOS MORAIS. REDE SOCIAL. FACEBOOK. OFENSAS. PESSOA JURÍDICA. HONRA SUBJETIVA. IMPERTINÊNCIA.

HONRA OBJETIVA. LESÃO. [...].

1. O propósito recursal é determinar se as manifestações da recorrida na rede social Facebook têm o condão de configurar dano moral indenizável à pessoa jurídica recorrente.

2. Ao disponibilizarem informações, opiniões e comentários nas redes sociais na internet, os usuários se tornam os responsáveis principais e imediatos pelas consequências da livre manifestação de seu pensamento, a qual, por não ser ilimitada, sujeitalhes à possibilidade de serem condenados pelos abusos que venham a praticar em relação aos direitos de terceiros, abrangidos ou não pela rede social.

$[\ldots]$

(STJ, T3, REsp 1.650.725/MG, Rel. Min. Nancy Andrighi, j. em 18.05.2017).

CONFLITO NEGATIVO DE COMPETÊNCIA. [...] DIVULGAÇÃO DE IMAGEM PORNOGRÁFICA DE ADOLESCENTE VIA WHATSAPP E EM CHAT NO FACEBOOK. [...]

3. Situação em que os indícios coletados até o momento revelam que as imagens da vítima foram trocadas por particulares via Whatsapp e por meio de chat na rede social Facebook.

4. Tanto no aplicativo WhatsApp quanto nos diálogos (chat) estabelecido na rede social Facebook, a comunicação se dá entre destinatários escolhidos pelo emissor da mensagem. Trata-se de troca de informação privada que não está acessível a qualquer pessoa.

$[\ldots]$

(STJ, S3, CC 150.564/MG, Rel. Min. Reynaldo Soares da Fonseca, j. em 26.04.2017).

41 PROCESSO PENAL. [...]. CRIME DE AMEAÇA E CONTRAVENÇÃO DE PERTURBAÇÃO DA TRANQUILIDADE PRATICADOS POR MEIO DA INTERNET. INDÍCIOS DE TRANSNACIONALIDADE. INEXISTÊNCIA. COMPETÊNCIA DA JUSTIÇA ESTADUAL. [...]

1. Hipótese em o conflito se estabeleceu em virtude de queixa-crime apresentada pelo fato de um suposto hacker enviar ameaças e manipular diversos adolescentes e pais de um mesmo ciclo de amizade e convivência, por meio de e-mails, Orkut, Twitter e Facebook.

2. A jurisprudência desta Corte Superior é no sentido de que, embora se trate de crime praticado por meio da rede mundial de computadores, necessária se faz a existência de indícios mínimos de extraterritorialidade para que seja determinada a competência da Justiça Federal. A mera utilização da internet não basta, por si só, para caracterizar a transnacionalidade do delito.

$[\cdots]$

(STJ, S3, AgRg no CC 118.394/DF, Rel. Min. Ribeiro Dantas, j. em 10.08.2016)

PROCESSUAL PENAL E PENAL. HABEAS CORPUS. PRISÃO PREVENTIVA. FUNDAMENTAÇÃO CONCRETA. ILEGALIDADE. AUSÊNCIA.

1. Apresentada fundamentação concreta para a decretação da prisão preventiva, evidenciada na periculosidade do paciente, uma vez que teria ameaçado sua ex-companheira e sua filha, bem como ameaçou a testemunha Patrícia e a vítima, por meio da rede social conhecida como "Facebook", não há que se falar em ilegalidade a justificar a

concessão da ordem de habeas corpus.

2. Habeas corpus denegado.

(STJ, T6, HC 325.233/SC, Rel. Min. Nefi Cordeiro, j. em 20.08.2015). 
gerados por terceiros, mas pelo próprio meio de comunicação, que, portanto, é responsável pela manifestação.

\subsubsection{Blogs}

O Blog, normalmente, se volta a uma temática específica, e, após cada notícia, está aberto aos visitantes, compreendidos como "terceiros", que se manifestem. Dessa forma, há possibilidade de que usuários, não integrantes do corpo editorial, possam vir a postar expressões difamatórias, e, em alguns casos, caluniosas.

De tal arte, na internet, é possível se deparar com conteúdo ofensivo, tais como: a difamação, a injúria, violação à privacidade ${ }^{42}$, afronta ao direito à imagem, bem como violações a direitos autorais, ao segredo industrial, entre outros. Assim, havendo ameaça ou lesão a bem jurídico tutelado juridicamente, uma das respostas do sistema jurídico consiste na responsabilidade civil dos provedores ou diretamente dos violadores de tais direitos. Passamos a examinar as questões que têm chegado aos tribunais.

\section{Da RESPONSABILIDADE CIVIL DOS PROVEDORES DE APLICAÇÃo À LUZ DA JURISPRUDÊNCIA DO SUPERIOR Tribunal de JUSTIÇA}

\subsection{Dos antecedentes da responsabilidade civil dos provedores}

Ao longo do tempo, o tratamento jurídico acerca da responsabilidade civil dos provedores passou por modificações. Em um primeiro momento, como visto, vivia-se em um cenário em que a própria aplicação do direito estatal, no ciberespaço, foi colocada em xeque. No entanto, diante da inarredável necessidade de solucionar conflitos que inevitavelmente surgiram, resultados da colisão de uma pretendida irrestrita liberdade de expressão com a invocação de consagrados direitos de personalidade (privacidade ${ }^{43}$, honra, imagem

42 Nas últimas décadas, vem crescendo o envolvimento dos tribunais de todos os países na proteção da intimidade e da vida privada. As constituições europeias mais antigas não previram a proteção de tais direitos. Todavia, como a Convenção Europeia dos Direitos do Homem, de 1950, previu, em seu art. $8^{\circ}$, a proteção da vida privada, a Corte Europeia dos Direitos do Homem, sediada em Estrasburgo, muitas vezes é instada a decidir casos a respeito de tal direito, ajudando, assim, a construir e a expandir seu conceito. No caso Niemitz v. Alemanha, por exemplo, julgado em 16.12.1992, a C.E.D.H. considerou que a noção de vida privada não se circunscreveria ao círculo íntimo da vida pessoal que cada um pode viver de forma escondida do mundo exterior, abrangendo também o direito de interação com outros indivíduos. Sobre esse e outros casos semelhantes, v. SARMENTO E CASTRO, Catarina. Direito da Informática, Privacidade e Dados Pessoais. Coimbra: Almedina, 2005. p. 26. Como quase todos os conceitos, o significado de privacidade ou intimidade evolui ao longo do tempo, sofrendo não só a influência dos novos valores sociais e estilos de vida individuais, como também o impacto das novas tecnologias. Compare-se, por exemplo, o que Justice Louis Brandeis, disse sobre privacy no caso Olmstead v. United States, em 1928 - "is the most comprehensive of rights and the right most valued by civilized men" - com o que afirmou Scott McNealy, CEO da Sun Mycrosystems, em 1999: “you have zero privacy anyway. Get over it.” Sobre a evolução do conceito de privacidade, v. JONES, Meg Leta. CRTL+Z: The Right to be Forgotten. New York: New York University Press, 2016. p. 82, bem como confira-se principalmente as páginas de Stefano Rodotà a respeito da evolução do conceito da privacy, especialmente após o advento do mundo digital. Rodotà recorda como a privacy fora concebida por Warren e Brandeis como um direito excludente, o de afastar o olhar indesejado (right to be let alone), mas posteriormente passou a ser um direito finalizado a tornar possível a construção da própria identidade, ou o direito de controlar o uso que outras pessoas fazem das informações que nos dizem respeito (Alan Westin). Posteriormente passou a significar também a tutela de escolhas de vida contra qualquer forma de controle público e de estigma social (L Friedman), ou a imposição de limites que impeçam que qualquer um seja simplificado, reduzido a objeto ou avaliado fora do seu contexto (J. Rosen), até chegar ao conceito de direito de escolher livremente seu próprio modo de viver (F. Rigaux) ou o direito de manter o controle sobre suas próprias informações e de determinar as modalidades de construção da própria esfera privada (Rodotà). Na época em que vivemos, o grande desafio, segundo Rodotà, é que minha identidade não seja mais "aquilo que afirmo ser", mas sim "aquilo que o Google diz que eu sou" - v. RODOTÀ, Stefano. Il diritto di avere diritti. Bari. Laterza, 2012. p. $319-321$ e 327. 43 Especialmente a privacidade vem sentindo o impacto da difusão em escala geométrica da internet. J. Solove referiu que "a internet está criando novos e atormentadores malefícios para a privacidade, uma vez que deu às pessoas uma possibilidade sem precedentes de disponibilizar e disseminar ao redor do mundo informação umas sobre as outras. Para enfrentar esses problemas, 
etc.), percebeu-se que, inevitavelmente, deveria haver lugar nesse novo mundo para a responsabilidade civil, sem falar de eventual invocação do direito de resposta, garantido constitucionalmente ${ }^{44}$.

Admitida, portanto, a inexorável aplicação do instituto da responsabilidade civil, surge a discussão sobre seu fundamento: responder-se-ia de forma objetiva ou somente nas hipóteses da presença da culpa?

Num primeiro momento, ao se tratar da responsabilidade dos provedores por danos causados a particulares no ambiente do ciberespaço, pretendeu-se a aplicação da teoria do risco da empresa, de feição objetiva, tanto no Brasil como no exterior.

$\mathrm{Na}$ Itália, Francesco Ciommo lembrava que os provedores desenvolvem uma atividade organizada, com fins lucrativos. Assim, quando chegaram aos tribunais os primeiros ilícitos praticados no ciberespaço, os provedores foram vistos como o bolso (tasca) seguro capaz de garantir uma tutela reparatória a pessoas prejudicadas por ilícitos praticados por sujeitos que permaneciam anônimos. Entendia-se que, como os prestadores de serviços telemáticos tinham vantagem econômica, também deveriam assumir o encargo de suportar os prejuízos sofridos pelas vítimas, independente de apuração de culpa própria. ${ }^{45}$ Tratava-se da aplicação do velho princípio genérico segundo o qual cuius commoda, eius et incommoda (quem recebe os cômodos, suporta também os incômodos), ou ubi emolumentum, ibi onus (onde estão os emolumentos, ali também estão os ônus).

Os adeptos da responsabilidade objetiva defendiam que os provedores poderiam utilizar programas-filtro, quando, antecipadamente, através de um prévio controle, preveniriam o cometimento de ilícitos. Para tanto, poderiam efetuar ou um controle amplo e prévio ou, mais realisticamente, um controle por amostragem, ou, ainda, um controle somente a posteriori, removendo os conteúdos tidos como ilícitos ou inconvenientes ${ }^{46}$.

Posteriormente, aplicou-se a responsabilidade vicária, respondendo o provedor pelo ilícito somente quando houvesse uma possibilidade concreta de controle das ações dos terceiros, tendo agido com omissão. É o mesmo doutrinador italiano quem assim se manifesta:

Si provò, allora, a battere una strada parzialmente diversa sostenendo la dottrina, c.d. vicarious liability, in base alla quale risponde dell'illecito chi, avendo il diritto e la possibilità concreta di controllare le azioni dell'autore del fatto, omette di impedire il verificarsi dell'evento lesivo e ne trae profitto. ${ }^{47}$

Posteriormente, quando se abandonou a fase inicial de uma relativa anomia no setor e praticamente todos os países passaram a dotar-se de marcos civis regulatórios, passou-se a adotar, de forma predominante (revelando a óbvia influência dos potentes provedores sobre os legisladores nacionais), a responsabilidade subjetiva. No Brasil, essa é a fase em que nos encontramos e que passamos especificamente a abordar, especialmente à luz da jurisprudência da corte superior ordinária que tem a missão institucional de uniformizar o entendimento a respeito desse importante tema.

\subsection{A Jurisprudência do Superior Tribunal de Justiça e a responsabilidade dos provedores.}

A partir do estudo do ciberespaço e do conteúdo ofensivo gerado por terceiros, bem como da identificação de fases da responsabilidade civil online, é que se busca, a partir da jurisprudência do Superior Tribunal

necessitamos repensar a privacidade para a era da Informação" - apud LONGHI, João Victor Rozatti. Marco civil da internet no Brasil: breves considerações sobre seus fundamentos, princípios e análise crítica do regime de responsabilidade civil dos provedores. In: MARTINS, Gulherme Magalhães (Coord.). Direito Privado \& Internet. São Paulo: Atlas, 2014. p. 104-146, p. 112-113.

44 VAINZOF, Rony. Da responsabilidade por danos decorrentes de conteúdo gerado por terceiros. In: DEL MASSO, Fabiana; ABRUSSIO, Juliana; FLORÊNCIO FILHO, Marco Aurelio (Org.). Marco civil da internet. São Paulo: Revista dos Tribunais, 2014 . p. 182. 45 CIOMMO, Francesco. Programmi-filtro e criteri di imputazione/esonero della responsabilità on-line. A proposito della sentenza Google/Vivi Down. Il Diritto dell'Informaz̧ione e Dell'Informatica, Roma, v. 26, n. 6, p. 829-857, nov./dez. 2010. p. 835.

46 CIOMMO, Francesco. Programmi-filtro e criteri di imputazione/esonero della responsabilità on-line. A proposito della sentenza Google/Vivi Down. Il Diritto dell'Informaz̧ione e Dell'Informatica, Roma, v. 26, n. 6, p. 829-857, nov./dez. 2010. p. 831.

47 CIOMMO, Francesco. Programmi-filtro e criteri di imputazione/esonero della responsabilità on-line. A proposito della sentenza Google/Vivi Down. Il Diritto dell'Informazione e Dell'Informatica, Roma, v. 26, n. 6, p. 829-857, nov./dez. 2010. p. 836. 
de Justiça, colacionar casos que possam auxiliar na construção do atual cenário da responsabilidade civil dos provedores de aplicação, no ordenamento jurídico brasileiro.

Importa salientar que foram escolhidos processos que retratam o que, hodiernamente, vem sendo aplicado. Cada um deles contribuirá, em sua especificidade, para essa finalidade. É o que se passa analisar.

\subsubsection{Da Classificação dos Provedores e do tratamento jurídico sobre responsabilidade civil}

No julgamento do Recurso Especial sob o no 1.642.997/RJ (j. em 12.09.2017) ${ }^{48}$, é possível extrair relevantes conceitos técnicos e sólidas posições jurídicas acerca da responsabilidade civil dos provedores. A demanda proposta pelo internauta objetivou a condenação em danos morais, em desfavor de Facebook Serviços Online do Brasil Ltda., por dano à sua imagem. A temática está ligada, portanto, à eventual responsabilidade civil solidária da rede social em comento, por conteúdos postados por terceiros.

Como importante contribuição, o aresto passa a promover uma classificação dos provedores, à luz do Marco Civil da Internet (MCI - Lei 12.965 de 2014), reconhecendo a "multiplicidade de atores" na internet, na medida em que são oferecidos "diferentes tipos de serviços e utilidades para os usuários". De modo geral, foram identificadas duas espécies de prestadores: provedores de conexão e de aplicação, na linha do MCI ${ }^{49}$.

Os provedores de conexão são aqueles que oferecem "a habilitação de um terminal para envio e recebimento de pacotes de dados pela internet, mediante a atribuição ou autenticação de um endereço IP", conforme preceitua o artigo $5^{\circ}$, V do MCI. Ou seja, são os prestadores de serviço que dão acesso ao ciberespaço, permitindo aos usuários ingressarem no mundo virtual. São exemplos, em nível nacional, as empresas do setor de telecomunicações, como é o caso da Brasil Telecom, Vivo, Oi, entre outras, que oferecem esse

48 Eis a ementa do acórdão:

CIVIL E PROCESSUAL CIVIL. RECURSO ESPECIAL. FACEBOOK. AÇÃO DE REPARAÇÃO POR DANOS MORAIS. CONTEÚDO REPUTADO OFENSIVO. MONITORAMENTO. AUSÊNCIA. RESPONSABILIDADE. AFASTAMENTO. NOTIFICAÇÃO JUDICIAL. NECESSIDADE. [...]

2. O propósito recursal reside na definição do termo inicial da responsabilidade solidária da recorrente — uma provedora de aplicações de internet — por conteúdos gerados por terceiros que utilizam suas aplicações.

3. A verificação do conteúdo das imagens postadas por cada usuário não constitui atividade intrínseca ao serviço prestado pelos provedores de compartilhamento de vídeos, de modo que não se pode reputar defeituoso, nos termos do art. 14 do CDC, a aplicação que não exerce esse controle.

4. O dano moral decorrente de mensagens com conteúdo ofensivo inseridas no site pelo usuário não constitui risco inerente à atividade dos provedores de compartilhamento de vídeos, de modo que não se lhes aplica a responsabilidade objetiva prevista no art. 927, parágrafo único, do CC/02.

5. Sobre os provedores de aplicação, incide a tese da responsabilidade subjetiva, segundo a qual o provedor de aplicação torna-se responsável solidariamente com aquele que gerou o conteúdo ofensivo se, ao ser notificado a respeito da lesão, não tomar providências para a sua remoção. Precedentes.

6. Diante da ausência de disposição legislativa específica, este STJ havia firme jurisprudência segundo a qual o provedor de aplicação passava a ser solidariamente responsável a partir do momento em que fosse de qualquer forma notificado pelo ofendido.

7. Com o advento da Lei 12.965/2014, o termo inicial da responsabilidade do provedor de aplicação foi postergado no tempo, iniciando-se tão somente após a notificação judicial do provedor de aplicação.

8. A regra a ser utilizada para a resolução de controvérsias deve levar em consideração o momento de ocorrência do ato lesivo ou, em outras palavras, quando foram publicados os conteúdos infringentes: (i) para fatos ocorridos antes da entrada em vigor do Marco Civil da Internet, deve ser obedecida a jurisprudência desta corte; (ii) após a entrada em vigor da Lei 12.965/2014, o termo inicial da responsabilidade da responsabilidade solidária do provedor de aplicação, por força do art. 19 do Marco Civil da Internet, é o momento da notificação judicial que ordena a retirada de determinado conteúdo da internet.

9. Recurso especial conhecido e provido.

(STJ, REsp 1.642.997/RJ, T3, Rel. Min. Nancy Andrighi, j. em 12.09.2017)

49 Como se sabe, anteriormente à Lei 12.965/14 (M.C.I.), doutrinariamente se costumava classificar de forma mais detalhada os diversos tipos de provedores. Alguns distinguiam provedores de conteúdo, provedores de serviços e provedores de rede. Outros apresentavam classificações ainda mais miúda, distinguindo os provedores de backbone, provedores de conteúdo e informação, provedores de acesso, provedores de hospedagem e provedores de correio eletrônico. A Lei 12.965/14 simplificou a situação, distinguindo os provedores de conexão dos provedores de aplicações de internet. Sobre isso, veja-se MIRAGEM, Bruno. Direito Civil: Responsabilidade Civil. São Paulo: Saraiva, 2015. p. 819-820; bem como LEONARDI, Marcel. Responsabilidade Civil dos Provedores de Serviços de Internet. São Paulo: J. Oliveira, 2005. p. 19-32. 
serviço. Segundo o MCI, em seu artigo 18, o provedor de conexão não responde, civilmente, por danos decorrentes de conteúdos gerados por terceiros ${ }^{50}$, o que é técnica e juridicamente adequado, visto que, nesse serviço, apenas se viabiliza o acesso, dá-se a porta de entrada, não se oferece aplicações, não havendo qualquer envolvimento com conteúdo. Usando uma outra imagem, seria como pretender-se responsabilizar quem construiu e mantém uma rodovia, pelos danos causados por um veículo a outro, em virtude de colisão que nada tivesse a ver com o estado da rodovia em si.

Por sua vez, os provedores de aplicação, segundo o artigo 5, VII, do MCI, voltam-se "ao conjunto de funcionalidades que podem ser acessadas por meio de um terminal conectado à internet", e, nesse caso, as funcionalidades são exemplificadas como: o oferecimento de serviço de correio eletrônico (Gmail, Hotmail, entre outros), hospedagem/armazenamento de dados (serviços de Cloud Computing, como a Amazon, Google, Dropbox etc.), disponibilização de imagens, inclusive, com a finalidade de compartilhamento (Youtube), e, finalmente, as redes sociais, como é o caso do Facebook, em que há conteúdo na sua plataforma.

Assim, o julgado classificou o Facebook como um provedor de aplicação, tendo em vista permitir a criação de um "perfil", com a "formação de comunidades virtuais", viabilizando a troca de "opiniões e comentários de seus usuários", tendo destacado suas funcionalidades oferecidas. Incumbe destacar que a decisão registrou que referido provedor "não exerce nenhuma forma de editoração ou controle prévio" do conteúdo que é gerado por terceiros.

A contribuição do julgado, sob o prisma acadêmico, passa pelo estudo aprofundado da responsabilidade civil em relação ao tema e pela busca de alcançar a adequada classificação, trazendo à lume reflexões sobre "o limite da responsabilidade civil dos provedores de aplicações por conteúdos que — mesmo armazenados ou de alguma forma manipulados pelo provedor — são em última análise gerados por terceiros.”

No corpo do acórdão são expostos os três entendimentos sucessivos sobre a matéria: a) irresponsabilidade do provedor; b) sua responsabilidade objetiva; c) responsabilidade subjetiva.

A tese da irresponsabilidade civil tem como fundamento o fato de que o conteúdo foi gerado por terceiros, não pelo provedor de aplicação. Nos Estados Unidos, chegou-se a comparar o provedor que hospeda websites a uma livraria, que nesse caso não responde pelo conteúdo dos livros vendidos ${ }^{51}$. Logo, toda e qualquer medida de responsabilização deveria ser tomada em desfavor do ofensor, operando-se a ilegitimidade passiva do prestador de serviço. Esta tese inicial acabou desacolhida no ordenamento jurídico brasileiro.

Por sua vez, os defensores da responsabilidade objetiva, a seu turno, sustentaram a presença de "risco na atividade", ou mesmo, o "defeito no serviço". Contudo, a posição consolidada do Superior Tribunal de Justiça, antes mesmo da entrada em vigor do artigo 19 do MCI, já era no sentido da inaplicabilidade da responsabilidade objetiva à hipótese, dado que "não considera como atividade intrínseca dos provedores de aplicações de internet o prévio monitoramento das informações e conteúdos que trafegam e são publicadas em seus serviços e plataformas".

Acolheu-se, portanto, a tese legal da responsabilidade subjetiva e solidária pelos danos gerados por terceiros em razão do provedor de aplicação, ciente da ofensa, não ter tomado "providências necessárias para sua remoção". A dúvida que então foi dirimida envolveu a discussão sobre o termo a quo da ciência do pro-

50 Embora os provedores de conexão ou de acesso, por serem fornecedores de serviço, respondam objetivamente perante seus usuários/consumidores, pelos defeitos eventualmente apresentados pelo serviço prestado, pois se trata de relação jurídica regida pelo CDC. Sobre esses aspectos, v. BRANT, Cássio Augusto Barros. Marco Civil da Internet: Comentários sobre a lei 12.965/2014. Belo Horizonte: D’Plácido, 2014. p. 227. Arnaldo Rizzardo comenta possível responsabilidade de provedor de serviços pela “contaminação de programas por vírus que passam para os computadores e se alojam nos equipamentos, provenientes de e-mails emitidos ou enviados", "pois a mensagem se dá de um e-mail para outro e-mail através do portal da operadora, a quem cabe colocar em operação mecanismos de prevenção, de modo a estancar a transmissão" - RIZZARDO, Arnaldo. Responsabilidade Civil. 5. ed. Rio de Janeiro: Gen/Forense, 2011. p. 835.

51 VANCIM, Adriano Roberto; NEVES, Fernando Frachone. Marco Civil da Internet: Anotações à Lei n. 12.965/2014. Leme: Mundo Jurídico, 2014. p. 97. 
vedor para fins de apuração de culpa: a comunicação feita pelo próprio ofendido ou a notificação de ordem judicial que determina a exclusão do conteúdo.

Antes do Marco Legal da Internet, adotara-se a tese de que a comunicação ao provedor poderia ser feita pelo próprio usuário, e, a partir daí, caso não fossem tomadas as providências necessárias, haveria responsabilização. No entanto, com o advento do artigo 19 do MCI, estabeleceu-se que a responsabilidade somente se opera se houver descumprimento de ordem judicial.

Importa destacar que, como situação excepcional, quanto às publicações que se configuram violação da intimidade por imagens de vídeos ou de outros materiais contendo cenas de nudez ou de atos sexuais de caráter privado, aplica-se como termo a quo da ciência do provedor, para fins de responsabilização, a notificação feita pelo próprio usuário ou por seu representante legal, a teor do artigo 21 do MCI. Procura-se, com essa exceção, agilizar a proteção das vítimas de tais tipos de postagens, sobretudo diante da onda de vazamento de fotos íntimas, conhecida como 'vingança pornô ${ }^{52}$. Nessa hipótese, a responsabilidade civil será subsidiária, não solidária, ou seja, caso não se logre obter a reparação do dano diretamente do responsável pela postagem das imagens, então se poderá acionar o provedor.

No caso concreto, à luz do posicionamento trazido, em face da ausência de notificação judicial, e, já estar-se diante da vigência do Marco Civil da Internet, não houve responsabilização do provedor.

\subsubsection{Da aferição de culpa: omissão com a necessidade de notificação judicial}

No Recurso Especial sob o no 1.641.133/MG (j. em 20.06.2017) ) $^{53}$, a matéria enfrentada versava sobre ação de indenização por danos morais cumulada com obrigação de remover conteúdo da internet, em desfavor de Google Brasil Internet Ltda.. No caso concreto, uma pessoa, utilizando-se de pseudônimo, havia publicado um "vídeo supostamente adulterado", que tinha como conteúdo a tentativa de compra de voto para prefeito municipal. A ação fora julgada procedente, condenando o provedor ao pagamento de $\mathrm{R} \$$ 50.000,00 (cinquenta mil reais). Também fora confirmada liminar anteriormente deferida para a remoção do conteúdo, com fixação de astreintes. Em sede de apelação, foi mantida a sentença. O provedor recorreu.

Quanto à responsabilidade civil da Google, no caso concreto, afirmou-se que, em face da funcionalidade oferecida (o aplicativo Youtube), que permite aos usuários hospedar (host) e compartilhar (share) seus vídeos no mundo virtual, o mesmo figura como provedor de aplicação. Assim, tal atividade desafia a aplicação do artigo 19 do MCI, com sua previsão de responsabilização com base na culpa. Esclareceu-se que o Google, em que pese não tenha a obrigação de monitorar ou realizar controle prévio de conteúdo, fora notificado judicialmente, por mais de uma vez, para a remoção do conteúdo, nada tendo feito. Assim, foi mantida,

52 JESUS, Damásio de; MILAGRE, José Antonio. Marco Civil da Internet-Comentários à Lei n. 12.965/14. São Paulo: Saraiva, 2014, p. 70 .

53 Assim se encontra ementado o acórdão (na parte que interessa):

CIVIL E PROCESSUAL CIVIL. RECURSO ESPECIAL. GOOGLE. YOUTUBE. AÇÃO DE REPARAÇÃO POR DANOS MORAIS. CONTEÚDO REPUTADO OFENSIVO. DANO MORAL. RESPONSABILIDADE SUBJETIVA DO PROVEDOR. NOTIFICAÇÃO JUDICIAL. DESCUMPRIMENTO. RESPONSABILIDADE SOLIDÁRIA COM OFENSOR. [...]

$[\ldots]$

3. Esta Corte fixou entendimento de que “(i) não respondem os provedores objetivamente pela inserção no site, por terceiros, de informações ilegais; (ii) não podem ser obrigados a exercer um controle prévio do conteúdo das informações postadas no site por seus usuários; (iii) devem, assim que tiverem conhecimento inequívoco da existência de dados ilegais no site, removê-los imediatamente, sob pena de responderem pelos danos respectivos; (iv) devem manter um sistema minimamente eficaz de identificação de seus usuários, cuja efetividade será avaliada caso a caso". Precedentes.

4. Aos provedores de aplicação, aplica-se a tese da responsabilidade subjetiva, segundo a qual o provedor de aplicação torna-se responsável solidariamente com aquele que gerou o conteúdo ofensivo se, ao tomar conhecimento da lesão que determinada informação causa, não tomar as providência necessárias para a sua remoção. Precedentes.

$[\ldots]$

7. Recurso especial conhecido e não provido.

(STJ, T3, REsp 1.641.133/MG, Rel. Min. Nancy Andrighi, j. em 20/06/2017). 
integralmente, a condenação em razão de sua responsabilidade subjetiva e solidária, na situação em comento.

\subsubsection{Da Necessidade de indicação de URL (Uniform Resource Locator)}

Em Recurso Especial sob o no 1.629.255/MG (j. em 22/08/2017) ${ }^{54}$, envolvendo pretensão de obrigação de fazer cumulada com pedido de reconhecimento de danos morais, em desfavor de Facebook Serviços Online do Brasil Ltda. e outros, a autora afirmara que o corréu H.R.A. havia publicado vídeos em rede social, com notícias falsas relativamente à sua conduta profissional. Em sede de tutela de urgência antecipada, foi deferida ordem para "imediata retirada de todas as matérias, notícias, divulgações e/ou comentários que atentem contra a honra, a imagem e a dignidade da requerente, publicados no perfil do FACEBOOK do requerido H.R.A. e procedam à remoção do blog opovotemrazao.com.br da rede mundial de computadores". O provedor Facebook alegou a impossibilidade da remoção do conteúdo, diante da ausência de URL (Uniform Resource Locator), que consiste no endereço da página na internet, onde se encontra a ofensa.

Dentre outros aspectos tratados no voto da Relatora, já enfrentados nas demandas acima referidas, a Ministra Andrighi analisou os "Princípios de Manila sobre Responsabilidade Civil dos Intermediários", publicados em 30 de maio de 2015 (https://www.manilaprinciples.org/pt-br), resultado de um esforço de organizações da sociedade civil de inúmeros países do globo, vinculadas ao setor. Referidos comandos advertem que a comunicação na internet vem sendo facilitada por intermediários, como provedores e redes sociais, e, havendo responsabilidade civil destes por conteúdos gerados por terceiros, haverá um forte impacto no direito dos usuários, na liberdade de expressão, na liberdade de associação e no direito à privacidade. Os princípios de Manila são os seguintes:

1) Os intermediários devem ser protegidos por lei da responsabilização dos conteúdos produzidos por terceiros; 2) Não se deve solicitar a remoção de conteúdo sem ordem de uma autoridade judicial; 3) Requisições de restrições de conteúdo devem ser claras, não ambíguos e seguir o devido processo; 4) Leis, ordens e práticas de restrição de conteúdos devem seguir o teste de necessidade e proporcionalidade; 5) Leis, políticas e práticas de restrição de conteúdo devem respeitar o devido processo; 6) Transparência e prestação de contas devem ser integradas em leis e em políticas e práticas de restrição de conteúdos.

O acórdão fundou-se no princípio n 2, dos "Princípios de Manila", a saber:

a. Os intermediários não devem ser obrigados a restringir conteúdos a menos que uma ordem

54 A ementa está vazada nos seguintes termos:

CIVIL E PROCESSUAL CIVIL. RESPONSABILIDADE CIVIL DO PROVEDOR DE APLICAÇÃO. REDE SOCIAL. FACEBOOK. OBRIGAÇÃO DE FAZER. REMOÇÃO DE CONTEÚDO. FORNECIMENTO DE LOCALIZADOR URL. COMANDO JUDICIAL ESPECÍFICO. NECESSIDADE. [...].

2. Esta Corte fixou entendimento de que “(i) não respondem objetivamente pela inserção no site, por terceiros, de informações ilegais; (ii) não podem ser obrigados a exercer um controle prévio do conteúdo das informações postadas no site por seus usuários; (iii) devem, assim que tiverem conhecimento inequívoco da existência de dados ilegais no site, removê-los imediatamente, sob pena de responderem pelos danos respectivos; (iv) devem manter um sistema minimamente eficaz de identificação de seus usuários, cuja efetividade será avaliada caso a caso".

3. Sobre os provedores de aplicação, incide a tese da responsabilidade subjetiva, segundo a qual o provedor de aplicação tornase responsável solidariamente com aquele que gerou o conteúdo ofensivo se, ao tomar conhecimento da lesão que determinada informação causa, não tomar as providências necessárias para a sua remoção.

4. Necessidade de indicação clara e específica do localizador URL do conteúdo infringente para a validade de comando judicial que ordene sua remoção da internet. O fornecimento do URL é obrigação do requerente. Precedentes deste STJ.

5. A necessidade de indicação do localizador URL não é apenas uma garantia aos provedores de aplicação, como forma de reduzir eventuais questões relacionadas à liberdade de expressão, mas também é um critério seguro para verificar o cumprimento das decisões judiciais que determinarem a remoção de conteúdo na internet.

6. Em hipóteses com ordens vagas e imprecisas, as discussões sobre o cumprimento de decisão judicial e, quanto à aplicação de multa diária, serão arrastadas sem necessidade até os Tribunais superiores.

7. O Marco Civil da Internet elenca, entre os requisitos de validade da ordem judicial para a retirada de conteúdo infringente, a "identificação clara e específica do conteúdo", sob pena de nulidade, sendo necessária a indicação do localizador URL.

8. Recurso especial provido.

(STJ, T3, REsp 1.629.255/MG, Rel. Min. Nancy Andrighi, j. em 22.08.2017). 
determinando que o material em questão é ilegal tenha sido emitida por uma autoridade judicial independente e imparcial.

b. Ordens para a restrição de conteúdos devem: I. Incluir uma determinação de que o conteúdo é ilegal na jurisdição em questão; II. Indicar o identificador de Internet e uma descrição do conteúdo ilegal; III. Fornecer evidências suficientes para documentar a base legal da ordem; IV. Quando aplicável, indicar o período de tempo no qual o conteúdo deve ser restringido.

c. Qualquer responsabilidade imposta a um intermediário deve ser proporcional e correlativa diretamente ao comportamento nocivo do intermediário ao não cumprir, de maneira apropriada, a ordem de restrição do conteúdo.

d. Os intermediários não devem ser responsabilizados pelo não cumprimento de qualquer ordem que não obedeça a este princípio.

Conforme alínea $\mathrm{b}, \mathrm{I}$, do princípio $\mathrm{n}^{\circ} 2$, há o dever de quem pleiteia a remoção de postagem ou vídeos "indicar o identificador de Internet e uma descrição do conteúdo ilegal". Nesse sentido, o Superior Tribunal de Justiça firmou posicionamento no sentido de ser imprescindível a indicação do URL (Uniform Resource Locator), para que seja possibilitado o cumprimento de ordem judicial precisa, nos moldes preconizados pelo art. 19, $\int 1^{\circ}$, do Marco Civil da Internet. Portanto, o aresto foi no sentido de afastar a determinação de remoção de conteúdo, "em razão da ausência de indicação do localizador URL", bem como a impossibilidade do provedor vir a ser responsabilizado por conteúdo feito por terceiro.

\subsubsection{Da Responsabilidade dos Provedores de Aplicação de Busca}

Merece análise a discussão havida no Agravo Interno em Recurso Especial sob o no 879.704/SP (j. em 22.08.2017 $)^{55}$, também envolvendo pretensão de obrigação de fazer cumulada com indenização por danos morais, movida por usuário da rede mundial em desfavor de Google Brasil Internet Ltda. O demandante buscou ordem de remoção e a consequente indenização sob a alegação de responsabilidade do provedor pela retirada de sites que veiculam informações inverídicas e ofensivas.

No caso em tela, o Superior Tribunal de Justiça posicionou-se no sentido de que o Google não é responsável por manter os sites no ar, apenas "divulgando a terceiros sua existência, através de análise de expressões neles contidas, digitadas pelos interessados”. No corpo do acórdão, com indicação de vários precedentes, constou que "a jurisprudência desta Corte é assente no sentido de que o provedor de hospedagem de blogs não está obrigado a realizar a prévia fiscalização das informações que neles circulam. Assim, não necessita de obter dados relativos aos conteúdos veiculados, mas apenas referentes aos autores dos blogs.”

\subsubsection{Da Responsabilidade Civil dos Blogs}

Com base na colisão aparente que se operou entre a liberdade de imprensa e os direitos de personalidade, no Recurso Especial sob o no 1.652.588/SP (j. em 26.09.2017) ${ }^{56}$ afirmou-se ter havido violação da honra e

55 Eis sua ementa:

AGRAVO INTERNO NO AGRAVO EM RECURSO ESPECIAL. CIVIL, PROCESSUAL CIVIL (CPC/1973). AÇÃO DE OBRIGAÇÃO DE FAZER C/C INDENIZAÇÃO POR DANOS MORAIS. [...] INTERNET. PROVEDOR DE PESQUISA VIRTUAL. FILTRAGEM PRÉVIA DAS BUSCAS. DESNECESSIDADE. RESTRIÇÃO DOS RESULTADOS. NÃO-CABIMENTO. CONTEÚDO PÚBLICO. DIREITO À INFORMAÇÃO. PRECEDENTES. [...] AGRAVO DESPROVIDO.

(STJ, T3, AgInt no AREsp 879.704/SP, Rel. Min. Paulo de Tarso Sanseverino, j. em 22/08/2017)

56 A ementa ficou assim redigida (com omissão dos aspectos não relevantes ao tema):

RECURSO ESPECIAL. AÇÃO INDENIZATÓRIA. RESPONSABILIDADE CIVIL. DANOS MORAIS. IMAGEM. IMPRENSA. PROGRAMA JORNALÍSTICO. DEVER DE INFORMAÇÃO. LIBERDADE DE IMPRENSA. LIMITES. ATO LÍCITO. COMPROVAÇÃO. REPORTAGEM COM CONTEÚDO OFENSIVO. REGULAR EXERCÍCIO DE DIREITO. NÃO CONFIGURAÇÃO. RESPONSABILIDADE SOLIDÁRIA DA EMISSORA E DOS JORNALISTAS. SÚMULA Nº 221/ STJ. [...]

1. Enquanto projeção da liberdade de manifestação de pensamento, a liberdade de imprensa não se restringe aos direitos de informar e de buscar informação, mas abarca outros que lhes são correlatos, tais como os direitos à crítica e à opinião. Por não possuir 
da imagem das pessoas referidas em matéria jornalística, também veiculada na internet, por ter havido abuso no direito de informar. A consequência foi a condenação solidária em danos morais do autor do escrito, bem como do veículo de divulgação, em aplicação da Súmula 221/STJ. ${ }^{57}$ Percebe-se, assim, que a súmula em comento, que havia consolidado jurisprudência envolvendo, originariamente, apenas publicações na imprensa escrita, passou a ter a sua aplicação estendida à radiodifusão, à televisão, bem como, no caso concreto, à disponibilização via internet. E, como peculiaridade do aresto, foi enfatizado que o mesmo dever de controle editorial que deve ser feito por uma empresa jornalística, no sentido de "evitar matérias ou artigos potencialmente danosos", também incumbe aos blogs, aplicando-se a Súmula 221/STJ.

A Ministra Nancy Andrighi, em processo anterior, havia assim explicado no que consistem os blogs:

Os blogs - contração da expressão inglesa weblog que, numa tradução literal, significa diário da rede (mundial de computadores) — consistem em páginas na Internet cuja estrutura possibilita sua rápida e constante atualização mediante acréscimo dos denominados posts (comentários, artigos), que em geral têm como foco a temática que dá origem — e muitas vezes intitula — o próprio blog. ${ }^{58}$

A respeito das publicações em blogs, há duas situações distintas, que conduzem a resultados jurídicos diversos. A primeira refere-se à prestação de "serviços de provedoria de informação", ou seja, quando matérias são disponibilizadas pelo próprio blog. Nesse caso, haverá responsabilidade solidária de seu titular juntamente ao autor da matéria publicada, em razão da possibilidade de controle prévio, já que inserido pelo titular da página. Na segunda situação, quanto aos posts dos internautas, terceiros não vinculados institucionalmente ao veículo de comunicação (não são colunistas, nem articulistas, nem representam a opinião do veículo de comunicação em questão), a responsabilidade civil se dará nos termos do artigo 19 do Marco Civil da Internet ${ }^{59}$, ou seja, somente se o titular do blog for notificado judicialmente para a retirada do conteúdo ofensivo produzido por terceiro e não o fizer, no prazo assinado pelo mandado judicial. ${ }^{60}$

Em julgamento proferido ainda antes da edição do MCI, mas que não conflita com sua regulamentação, a Ministra Nancy Andrighi já havia indicado as condições em que o responsável pelo blog responde pelos danos derivados de postagens ali efetuadas por terceiros:

\section{CIVIL E CONSUMIDOR. INTERNET. PROVEDOR DE CONTEÚDO. USUÁRIOS. IDENTIFICAÇÃO. DEVER. GUARDA DOS DADOS. OBRIGAÇÃO. [...]}

2. Recurso especial que discute os limites da responsabilidade dos provedores de hospedagem de blogs pela manutenção de dados de seus usuários.

3. Ao oferecer um serviço por meio do qual se possibilita que os usuários divulguem livremente suas opiniões, deve o provedor de conteúdo ter o cuidado de propiciar meios para que se possa identificar cada

caráter absoluto, encontra limitação no interesse público e nos direitos da personalidade, notadamente à imagem e à honra, das pessoas sobre as quais se noticia.

$[\ldots]$

3. A liberdade de radiodifusão não impede a punição por abusos no seu exercício, como previsto no Código Brasileiro de Telecomunicações, em disposição recepcionada pela nova ordem constitucional (art. 52 da Lei no 4.117/1962).

$[\ldots]$

7. Na hipótese de danos decorrentes de publicação pela imprensa, são civilmente responsáveis tanto o autor da matéria jornalística quanto o proprietário do veículo de divulgação (Súmula no 221/STJ). Tal enunciado não se restringe a casos que envolvam a imprensa escrita, sendo aplicável a outros veículos de comunicação, como rádio e televisão. Precedentes.

15. Recursos especiais não providos.

(STJ, T3, REsp 1.652.588/SP, Rel. Min. Ricardo Villas Boas Cueva, j. em 26.09.2017).

57 Súmula 221/STJ: "São civilmente responsáveis pelo ressarcimento de dano, decorrente de publicação pela imprensa, tanto o autor do escrito quanto o proprietário do veículo de divulgação."

58 BRASIL. Superior Tribunal de Justiça. REsp 1.138.138/SP. Terceira turma. Relatora: Ministra Nancy Andrighi, j. em 25.09.2012.

59 BRASIL. Lei 12.965/2014. Art. 19. Com o intuito de assegurar a liberdade de expressão e impedir a censura, o provedor de aplicações de internet somente poderá ser responsabilizado civilmente por danos decorrentes de conteúdo gerado por terceiros se, após ordem judicial específica, não tomar as providências para, no âmbito e nos limites técnicos do seu serviço e dentro do prazo assinalado, tornar indisponível o conteúdo apontado como infringente, ressalvadas as disposições legais em contrário.

60 BRASIL. Superior Tribunal de Justiça. REsp 1.381.610/RS. Terceira turma. Relatora: Ministra Nancy Andrighi, j. em: 03.09.2013. 
um desses usuários, coibindo o anonimato e atribuindo a cada imagem uma autoria certa e determinada. Sob a ótica da diligência média que se espera do provedor, do dever de informação e do princípio da transparência, deve este adotar as providências que, conforme as circunstâncias específicas de cada caso, estiverem ao seu alcance para a individualização dos usuários do site, sob pena de responsabilização subjetiva por culpa in omittendo. Precedentes.

\section{$[\ldots]$}

5. As informações necessárias à identificação do usuário devem ser armazenadas pelo provedor de conteúdo por um prazo mínimo de 03 anos, a contar do dia em que o usuário cancela o serviço.

6. Recurso especial a que se nega provimento.

(STJ, T3, REsp 1.417.641/RJ, Rel. Min. Nancy Andrighi, j. em 25.02.2014)

Referido acórdão, também, aborda, como se vê, a importante questão da manutenção dos dados que permitam identificar os usuários, "de modo a tentar minimizar os danos causados pelas ofensas praticadas pela internet", permitindo às vítimas a possibilidade de ajuizar ações de reparação de danos, como ponderam Farias, Braga Netto e Rosenvald, referindo que os provedores estão obrigados a armazenar tais dados pelo prazo de três anos, a contar da data do cancelamento do serviço, por ser este o prazo prescricional para as pretensões relativas à responsabilidade civil ${ }^{61}{ }^{62}$

\section{Considerações Finais}

Com base no estudo realizado, tornou-se possível tecer as seguintes considerações finais, a saber:

1) Diante do impacto das novas tecnologias no âmbito virtual, mas capazes de causar danos na esfera real e concreta da vida de relação, governos, paulatinamente, passaram a regular o mundo virtual, assim como já ocorrera no mundo físico;

61 FARIAS, Cristiano Chaves de; BRAGA NETTO, Felipe; ROSENVALD, Nelson. Novo Tratado de Responsabilidade Civil. 2. ed. São Paulo: Saraiva, 2017. p. 799.

62 Caso interessante de ponderação do direito à honra e à imagem-atributo, quando atingidos pela liberdade de expressão manifestada em postagem de blog, com referência à especificidade desse meio de expressão, foi julgado pelo Tribunal de Justiça do Rio Grande do Sul, em acórdão assim ementado:

AGRAVO DE INSTRUMENTO. SUBCLASSE RESPONSABILIDADE CIVIL. AÇÃO INDENIZATÓRIA C/C PRETENSÕES DE OBRIGAÇÃO DE FAZER E NÃO FAZER. PEDIDO DE ANTECIPAÇÃO DE TUTELA. DEFERIMENTO PARCIAL. EXCLUSÃO DAS REFERÊNCIAS INDEVIDAS AO NOME DO AUTOR E PROIBIÇÃO À REALIZAÇÃO DE NOVAS REFERÊNCIAS COM O MESMO TEOR. BLOGUEIRO. LIBERDADE DE IMPRENSA. DISTINÇÕES.

O direito fundamental de liberdade de expressão jornalística e de exercício do direito de informação que se reconhece à mídia regular (jornais, rádio, televisão) deve ser estendido, em princípio, aos novos meios de comunicação social, como são os blogs.

Todavia, há distinções entre um e outro meio que devem ser levados em consideração. De fato, [...] os grandes veículos de imprensa, pela expertise e profissionalismo de sua atividade, são dotados de mecanismos internos de moderação do conteúdo de suas opiniões, tipo de controle que não se encontra na atuação de um blogueiro. Os órgãos regulares de imprensa possuem conselhos editoriais, filtros internos que discutem quais as notícias que serão divulgadas, seu conteúdo e forma de exposição, exatamente por terem noção clara das fronteiras existentes, a fim de evitar os sensacionalismos irresponsáveis que muitas vezes nada mais servem do que para desacreditar a própria imprensa.

Por outro lado, órgãos regulares da imprensa normalmente têm capacidade econômica para suportar uma condenação judicial de reparação civil. Mas exatamente por saber que um excesso pode ter repercussão econômica negativa para a empresa é que muitas vezes se evitam publicações açodadas ou sem lastro em evidências concretas. O mesmo não ocorre com certos blogueiros que, muitas vezes desprovidos de patrimônio próprio, tendem a adotar a lógica da irresponsabilidade, já que nada têm a perder.

No caso dos blogueiros, portanto, não é sensato imaginar que se deva prestigiar a liberdade de imprensa, num primeiro momento, para que, se houver excesso, posteriormente, haja uma reparação econômica ex post, pois isso talvez não ocorra. Nessa hipótese, o dano restará sem reparação. Assim, quando cabível e possível, devem-se tomar providências para fazer cessar o dano de imediato. $[\ldots]$

(Agravo de Instrumento No 70064429327, Nona Câmara Cível, Tribunal de Justiça do RS, Rel. Eugênio Facchini Neto, j. em $24 / 06 / 2015)$ 
2) Representando notável ampliação da liberdade de expressão, hodiernamente, provedores de aplicação viabilizam inúmeras formas para que terceiros possam expressar a sua opinião, tal como ocorre nas redes sociais, bem como com a possibilidade de postar comentários em blogs. Depois de uma hesitação inicial, hoje se tem como incontroverso que, em homenagem à liberdade de expressão, não há como se pensar em controle prévio ou programas-filtro de tais manifestações;

3) A responsabilidade civil dos provedores de aplicação por conteúdo gerado por terceiros sofreu modificações ao longo do tempo, atravessando a responsabilidade objetiva, responsabilidade vicária, até chegar à responsabilidade subjetiva hoje vigorante;

4) A atual jurisprudência do Superior Tribunal de Justiça, em consonância com o Marco Civil da Internet, fixa algumas importantes diretrizes para a solução dos casos que surgem na vida real, dentre as quais destacamos as seguintes:

4.1) A diferenciação entre as duas espécies de provedores, segundo o próprio Marco Civil da Internet: provedores de conexão e de aplicação;

4.2) O provedor de conexão não responde, civilmente, por danos decorrentes de conteúdos gerados por terceiros, visto que, nesse serviço, apenas se viabiliza o acesso, dá-se a porta de entrada. Não se oferecem aplicações, tampouco há qualquer envolvimento com conteúdo;

4.3) Quanto aos provedores de aplicação, há responsabilidade subjetiva e solidária pelos danos gerados por terceiros, na hipótese de, uma vez ciente da ofensa, não venha a tomar providências necessárias para sua remoção;

4.4) Relativamente aos fatos ocorridos após a vigência do Marco Civil da Internet, a ciência deve ser feita pela via judicial, com a indicação da URL (Uniform Resource Locator), que consiste no endereço da página na internet, onde se encontra a ofensa;

4.5) Como situação excepcional, quanto às publicações que configuram violação do reduto mais tipicamente íntimo das pessoas, com a divulgação de imagens de vídeos ou de outros materiais contendo cenas de nudez ou de atos sexuais de caráter privado, aplica-se como termo a quo da ciência do provedor, para fins de responsabilização, a notificação feita pelo próprio usuário ou por seu representante legal, a teor do artigo 21 do MCI;

4.6) Provedor de busca (como o Google) não é responsável por manter os sites no ar, apenas "divulgando a terceiros sua existência, através de análise de expressões neles contidas, digitadas pelos interessados", operando-se sua ilegitimidade passiva, na medida em que não há como lhe imputar o dever de retirar páginas de titularidade de terceiros do ar. Tampouco, há que se falar em dever de indenizar os danos causados por imagens ou informações localizáveis na rede mundial. Ressalva-se a questão do direito ao esquecimento, ainda sem regulamentação legal entre nós, embora com algum reconhecimento judicial. Não se trata, porém, de pretensão reparatória, mas sim de obrigação de fazer — retirada de determinados links;

4.7) Quanto aos blogs, a prestação de "serviços de provedoria de informação", ou seja, quando matérias são disponibilizadas pelo próprio blog, em caso de ofensa, haverá responsabilidade solidária de seu titular juntamente ao autor da matéria publicada, em razão da possibilidade de controle prévio, já que inserido pelo titular da página. Todavia, quanto aos posts dos internautas, terceiros não vinculados institucionalmente ao veículo de comunicação (não são colunistas, nem articulistas, nem representam a opinião do veículo de comunicação em questão), a responsabilidade civil se dará nos termos do artigo 19 do Marco Civil da Internet $^{63}$, ou seja, somente se o titular do blog for notificado judicialmente para a retirada do conteúdo ofensivo

63 BRASIL. Lei 12.965/2014.Art. 19. Com o intuito de assegurar a liberdade de expressão e impedir a censura, o provedor de aplicações de internet somente poderá ser responsabilizado civilmente por danos decorrentes de conteúdo gerado por terceiros se, após ordem judicial específica, não tomar as providências para, no âmbito e nos limites técnicos do seu serviço e dentro do prazo assinalado, tornar indisponível o conteúdo apontado como infringente, ressalvadas as disposições legais em contrário. 
produzido por terceiro e não o fizer, no prazo assinado pelo mandado judicial. ${ }^{64}$

Conclui-se, assim, que o Superior Tribunal de Justiça vem mantendo uma orientação jurisprudencial estável que, observando as diretrizes fixadas no Marco Civil da Internet, vem conseguindo garantir uma ampla liberdade de expressão, sem prévia censura e sem colocar obstáculos às empresas que atuam no mundo virtual, mas, ao mesmo tempo, oferecendo uma proteção razoável às vítimas que, ocasionalmente, sofrem violação a determinados direitos de personalidade, especialmente sua honra, imagem e privacidade.

\section{REFERÊNCIAS}

ASCENSÃO, José de Oliveira. Estudos sobre direito da internet e da sociedade da informação. Coimbra: Almedina, 2001.

AZAMBUjA, Celso Candido de. Psiquismo digital sociedade, cultura e subjetividade na era da comunicaşão digital. Nova Petrópolis: Nova Harmonia, 2012.

BAUMAN, Zygmunt; MAY, Tim. Aprendendo a pensar com a sociologia. Tradução de Alexandre Werneck. Rio de Janeiro: Zahar, 2010.

BRANT, Cássio Augusto Barros. Marco Civil da Internet: Comentários sobre a lei 12.965/2014. Belo Horizonte: D’Plácido, 2014.

BEZERRA, Tiago José de Souza Lima; MENEZES NETO, Elias Jacob de; MORAIS, Jose Luis Bolzan de. O projeto de lei de proteção de dados pessoais (PL 5276/2016) no mundo do big data: o fenômeno da dataveillance em relação à utilização de metadados e seu impacto nos direitos humanos. In: Revista Brasileira de Políticas Públicas, v. 7, n. 3, 2017.

CAVAZOS, Edward A.; MORIN, Gavino. Cyber-space and The Law: Your Rights and Duties in the On-Line World. Massachusetts: Massachusetts Institute of Technology, 1996.

CIOMMO, Francesco. Programmi-filtro e criteri di imputazione/esonero della responsabilità on-line. A proposito della sentenza Google/Vivi Down. Il Diritto dell'Informaz̧ione e Dell'Informatica, Roma, v. 26, n. 6, p. 829-857, nov./dez. 2010.

DE LUCCA, Newton. Alguns aspectos da responsabilidade civil no âmbito da Internet. In: DINIZ, Maria Helena; LISBOA, Roberto Senise (Coord.). O Direito Civil no Século XXI. São Paulo: Saraiva, 2003. p. 423470 .

FARIAS, Cristiano Chaves de; BRAGA NETTO, Felipe; ROSENVALD, Nelson. Novo Tratado de Responsabilidade Civil. 2. ed. São Paulo: Saraiva, 2017.

FRANZONI, Massimo. Il riscarcimento del danno per lesione dei diritti della personalità su internet In: NIVARRA, Luca; Ricciuto, Vincenzo (Org.). Internet e il diritto dei privati: persona e proprietà intelletuale nelle reti telematiche. Torino: Giappichelli, 2002. p. 127-136.

FURTADO, Gabriel Rocha. O marco civil da Internet: a construção da cidadania virtual. In: SCHREIBER, Anderson (Coord.). Direito e Mídia. São Paulo: Atlas, 2013. p. 236-254.

GAUDENZI, Andrea Sirotti. Diritto all'oblio: responsabilità e risarcimento del danno. Santarcangelo di Romagna: Maggioli Editore, 2017.

IASELLI, Michele. Come esercitare il diritto all'oblio in internet. Le procedure extragiudiziali, la tutela d'urgenza,

64 BRASIL. Superior Tribunal de Justiça. REsp 1.381.610/RS. Terceira turma. Relatora: Ministra Nancy Andrighi. Julgado em: 03 set. 2013. DJe 12 set. 2013 
il risarcimento danni. Roma: Dike Giuridica Editrice, 2017.

JAYME, Erik. O direito internacional privado do novo milênio: a proteção da pessoa humana face à globalização. Cadernos do Programa de Pós-Graduação em Direito - PPGDir./UFRGS, Porto Alegre, v. 1, n. 1, p. 133-146, mar. 2003.

JESUS, Damásio de; MILAGRE, José Antonio. Marco Civil da Internet: Comentários à Lei n. 12.965/14. São Paulo: Saraiva, 2014.

JONES, Meg Leta. CRTL+Z: The Right to be Forgotten. New York: New York University Press, 2016.

LASICA, J. D. Identity in the age of Cloud Computing. Washington: The Aspen Institute, 2009.

LEONARDI, Marcel. A garantia fundamental do direito à privacidade e à liberdade de expressão nas comunicações na condição ao pleno exercício do direito ao acesso à internet. In: LEITE, George Salomão; LEMOS, Ronaldo (Org.). Marco civil da internet. São Paulo: Atlas, 2014.

LEONARDI, Marcel. Responsabilidade Civil dos Provedores de Serviços de Internet. São Paulo: J. Oliveira, 2005.

LESSIG, Lawrence. Code Version 2.0. New York: Lawrence Lessig CC Attribution-ShareAlike, 2006. Versão Kindle.

LÉVY, Pierre. Cibercultura. Tradução de Carlos Irineu da Costa. São Paulo: Editora 34, 2008.

LEMOS JUNIOR, Eloy Pereira; ALVES, Edmar Warlisson de Souza; FIUZA, César Augusto de Castro. Uso indevido de redes sociais e aplicativos de mensagens instantâneas no ambiente laboral. In: Revista Brasileira de Políticas Públicas, v. 7, n. 3, 2017.

LEWICKI, Bruno. Realidade Refletida: Privacidade e Imagem na Sociedade Vigiada. In: TEPEDINO, Gustavo; FACHIN, Luiz Edson (Coord.). O Direito e o Tempo: Embates Jurídicos e Utopias Contemporâneas. Rio de Janeiro: Renovar, 2008. p. 103-113.

LONGHI, João Victor Rozatti. Marco civil da internet no Brasil: breves considerações sobre seus fundamentos, princípios e análise crítica do regime de responsabilidade civil dos provedores. In: MARTINS, Gulherme Magalhães (Coord.). Direito Privado \& Internet. São Paulo: Atlas, 2014. p. 104-146.

LORENZETTTI, Ricardo Luis. Teoria da decisão judicial: fundamentos de direito. Tradução de Bruno Miragem. Notas de Claudia Lima Marques. São Paulo: Revista dos Tribunais, 2010.

MACHADO, Alexandre Fragoso. Os Anunciantes, os Sites de Busca e os Links Patrocinados: Direito do Consumidor e Responsabilidade Civil. In: LOPEZ, Teresa Ancona; LEMOS, Patrícia Faga Iglecias; RODRIGUES JUNIOR, Otavio Luiz (Coord.). Sociedade de Risco e Direito Privado: desafios normativos, consumeristas e ambientais. São Paulo: Atlas, 2013. p. 644-677.

MANCINI, Anna. Justice et internet: une philosophie du droit pour le monde virtuel. Paris: Buenos Books International, 2004. Versão Kindle.

MARCONDES FILHO, Ciro. O rosto e a máquina. São Paulo: Paulus, 2013.

MAYER-SCHÖNBERGER, Victor. Delete: The Virtue of Forgetting in the Digital Age. Princeton: Princeton University Press, 2009.

MIRAGEM, Bruno. Direito Civil: Responsabilidade Civil. São Paulo: Saraiva, 2015.

MIRAGEM, Bruno. Responsabilidade por danos na sociedade de informação e proteção do consumidor: desafios atuais na regulação jurídica da internet. Revista de Direito do Consumidor, São Paulo, v. 70, p. 1-42, abr. 2009. Disponível em: <http://revistadostribunais.com.br/maf/api/tocectory?ndd=3\&tocguid=brroot\&st new $=$ true $>$. Acesso em: 24 jun. 2014.

PAESANI, Liliana Minardi. Direito e Internet: Liberdade de informação, privacidade e responsabilidade civil. 
5. ed. São Paulo: Atlas, 2012.

PARISI, Annamaria Giulia. Responsabilità e Sanzioni. In: SICA, Salvatore; D’ANTONIO, Virgilio; RICCIO, Giovanni Maria (a cura di). La nuova disciplina europea della privacy. Milanofiori Assago/Itália: Wolters Kluwer/CEDAM, 2016, p. 289-312.

PIZZETTTI, Franco. Privacy e il diritto europeo alla protęione dei dati personali: Il Regolamento europeu 2016/679. Torino: Giappichelli Editore, 2017.

RIZZARDO, Arnaldo. Responsabilidade Civil. 5. ed. Rio de Janeiro: Gen/Forense, 211.

RODOTÀ, Stefano. Il diritto di avere diritti. Bari. Laterza, 2012.

ROSSELLO, Carlo. Riflessioni. De Jure Condendo in materia di responsabilità del provider. Il Diritto dell'Informazione e Dell'Informatica, Roma, v. 26, n. 6, p. 617-629, nov./dez. 2010.

SANTAELLA, Lucia. Linguagens líquidas na era da mobilidade. São Paulo: Paulus, 2011.

SARMENTO E CASTRO, Catarina. Direito da Informática, Privacidade e Dados Pessoais. Coimbra: Almedina, 2005.

SCHMIDT, Eric; COHEN, Jared. A nova era digital: como será o futuro das pessoas, das nações e dos negócios. Tradução de Ana Beatriz Rodrigues, Rogério Durst. Rio de Janeiro: Intrínseca, 2013.

SCHWAB, Klaus. The fourth industrial revolution. Genebra: Wold Economic Forum, 2016.

SOUSA, Marcos Rogério de. Responsabilidade Civil pelo Conteúdo das Informações Transmitidas pela Internet. In: LOPEZ, Teresa Ancona; LEMOS, Patrícia Faga Iglecias; RODRIGUES JUNIOR, Otavio Luiz (Coord.). Sociedade de Risco e Direito Privado: desafios normativos, consumeristas e ambientais. São Paulo: Atlas, 2013. p. 678-698.

TEIXEIRA, Tarcísio. Marco civil da internet comentado. São Paulo: Almedina, 2016.

TELLINI, Denise Estrella. Regime de direito internacional privado na responsabilidade dos provedores de internet: Content Service Providers e Intermediary Service Providers pela qualidade dos serviços executados online. Porto Alegre: S. A. Fabris, 2006.

THIEFFRY, Patrick. Commerce électronique. Droit international et européen. Paris: Éditions Litec, 2002.

VAINZOF, Rony. Da responsabilidade por danos decorrentes de conteúdo gerado por terceiros. In: DEL MASSO, Fabiana; ABRUSSIO, Juliana; FLORÊNCIO FILHO, Marco Aurelio (Org.). Marco civil da internet. São Paulo: Revista dos Tribunais, 2014.

VANCIM, Adriano Roberto; NEVES, Fernando Frachone. Marco Civil da Internet: Anotações à Lei n. 12.965/2014. Leme: Mundo Jurídico, 2014. 
Para publicar na revista Brasileira de Políticas Públicas, acesse o endereço eletrônico www.rbpp.uniceub.br

Observe as normas de publicação, para facilitar e agilizar o trabalho de edição. 